Determination of Trace Rare Earth Impurities in Lutetium by X-Ray Excited Optical Luminescence

John Scott Tritten

A M. S. Thesis Submitted to Iowa State University, May 1974

\author{
Ames Laboratory, USAEC \\ Iowa State University \\ Ames, Iowa 50010
}

Date Transmitted: July 1974

PREPARED FOR THE U. S. ATOMIC ENERGY COMMISSION DIVISION OF RESEARCH UNDER CONTRACT NO. W-7405-eng-82

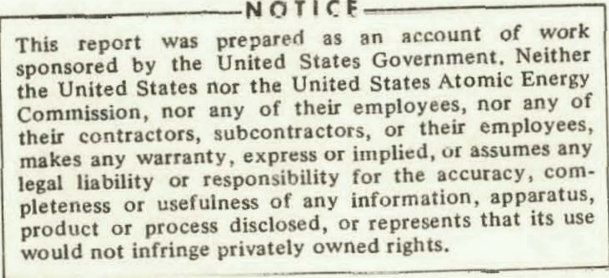




\section{DISCLAIMER}

This report was prepared as an account of work sponsored by an agency of the United States Government. Neither the United States Government nor any agency Thereof, nor any of their employees, makes any warranty, express or implied, or assumes any legal liability or responsibility for the accuracy, completeness, or usefulness of any information, apparatus, product, or process disclosed, or represents that its use would not infringe privately owned rights. Reference herein to any specific commercial product, process, or service by trade name, trademark, manufacturer, or otherwise does not necessarily constitute or imply its endorsement, recommendation, or favoring by the United States Government or any agency thereof. The views and opinions of authors expressed herein do not necessarily state or reflect those of the United States Government or any agency thereof. 


\section{DISCLAIMER}

Portions of this document may be illegible in electronic image products. Images are produced from the best available original document. 
This report was prepared as an account of work sponsored by the United States Government. Neither the United States nor the United States Atomic Energy Commission, nor any of their employees, nor any of their contractors, subcontractors, or their employees, makes any warranty, express or implied, or assumes any legal liability or responsibility for the accuracy, completeness or usefulness of any information, apparatus, product or process disclosed, or represents that its use would not infringe privately owned rights.

Available from: National Technical Information Service Department A

Springfield, VA 22151

Price: Micrufiche $\$ 1.45$

Printed Copy $\$ 5.4 .5$ 
iii

$$
\text { IS-T-644 }
$$

\title{
Determination of trace rare earth impurities in lutetium by X-ray excited optical luminescence
}

by

John Scott Tritten

\author{
A Thesis Submitted to the \\ Graduate Faculty in Partial Fulfillment of \\ The Requirements for the Degree of \\ MASTER OF SCIENCE \\ Department: Chemistry \\ Major: Analytical Chemistry
}

Approved:

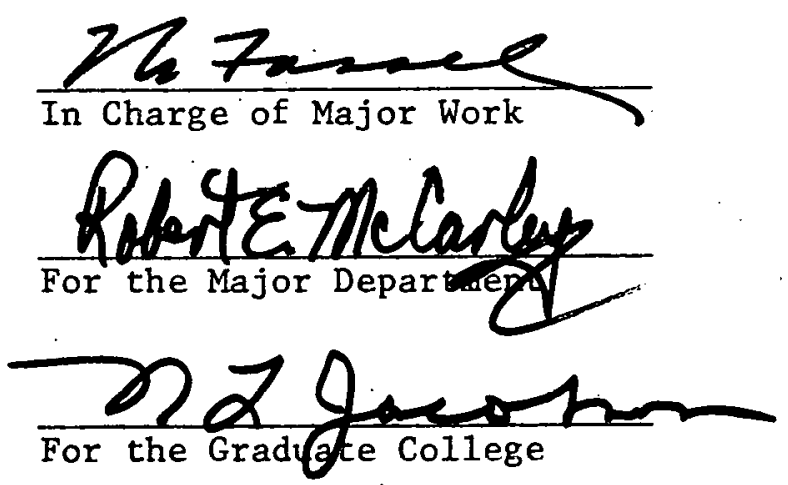

Iowa State University

Ames, Iowa

1974 
TABLE OF CONTENTS

$\underline{\text { Page }}$

INTRODUCTION

1

THEORY

5

$\begin{array}{ll}\text { EXPERIMENTAL APPARATUS AND PROCEDURES } & 10^{\circ}\end{array}$

$\begin{array}{ll}\text { Apparatus } & 10\end{array}$

$\begin{array}{ll}\text { Phosphor Research } & 10\end{array}$

Selection of the Internal Reference Element 24

Phosphor Optimization 33

Sample Preparation $\quad 40$

RESULTS $\quad 42$

Detection Limits $\quad 42$

Analytical Calibration Curves $\quad 44$

Prectsion $\quad .52$

$\begin{array}{ll}\text { Accuracy } & 52\end{array}$

$\begin{array}{ll}\text { SUMMARY } & 56\end{array}$

BIBLIOGRAPHY

ACKNOWLEDGMENTS $\quad \cdot 62$ 


\section{INTRODUCTION}

U1tra high purity rare earth elements are used extensively in several aspects of research and manufacturing. The rare earths, including the 15 lanthanides, yttrium, and scandium, are employed in phosphor research for the construction of color television tubes, lasers, and X-ray image intensifiers; in nuclear science for the production of control rod materials and neutron radiography imaging devices; In superalloy investigations; and in fundamental research. Probably most important in terms of future growth and diversification of the demand for rare earths are the inquiries currently being conducted on the chemical and physical properties of the rare earths themselves.

Each rare earth is being investigated more thoroughly and widely in Iight of these possible applications. In fact, research concerning chemical, physical, and phosphor properties of these elements has even increased the demand for high purity lutetium, the least common rare earth. These studies require a high purity lutetium especially free of other rare earth impurities because, for example, the efficiency of a rare earth phosphor host is quite dependent on rare earth impurities present at concentration levels less than a $\mu g$ of the impurity per gram of "pure" rare earth ( $\mathrm{ppm}$ ). In separations by commercial ion exchange methods, the rare earths most commonly found as impurities in lutetium are holmium, erbium, thulium, and ytterbium ${ }^{1}$ at levels from a fraction of a ppm to about 100 $\mathrm{ppm}$. If lutetium of this high purity is to be made regularly, then an extremely sensitive analytical technique must be avallable for quick, accurate, and inexpensive determinations of trace rare earth impurities in 
the lutetium matrix. Spectrophotometric analysis, ${ }^{2}$ emission and absorption spectroscopy, ${ }^{3-6}$ and $X$-ray fluorescence ${ }^{7,8}$ are sensitive at levels of approximately $10 \mathrm{ppm}$ or more, however accurate analyses at levels below ten ppm would require a time consuming preconcentration of the sample. 9 Although neutron activation analysis is a sensitive method for many elements at low levels; matrix interferences, 9,10 high expense, and long turnover time would make routine determination of the rare earth impurities difficult. ${ }^{11}$ Mass spectroscopic analyses are also very sensitive, but the inaccuracies encountered at low concentration values, $10,12,13$ the expense, and the time requirement limit the utility of this method. Three analytical techniques which could provide for the accurate determination of trace rare earth impurities in a rare earth matrix are based on the optical Iine luminescence of the rare earths in a solid host excited by efther ultraviolet (UV) light, electron beams (cathodoluminescence), or X-radiation. Ultraviolet excited Iuminescence has been extensively used in the determination of many rare earth impurities in a variety of solid hosts; ${ }^{14,15}$ even a method for the determination of rare earth Impurtities in lutetium has been devieloped by Poluekluv et al. ${ }^{16}$ Although the fact that the UV sources used for excitation are readily available in most laboratories makes this method convenient, the filtering of the exciting radiation from the measurement devices and the low sensitivity of the method for many elements at the sub-ppm level makes the method Impractical for impurity determinations in ultra-high purity rare earths. Cathodoluminescence is a very sensitive method used for rare earth impurity studies, ${ }^{17-19}$ but the scarcity of electron excitation equipment 
and the use of a vacuum in the determinations makes this technique inconvenient. 17

X-ray excited optical luminescence (XEOL) was first proposed as a method for the quantitative determination of rare earth impurities in solid crystals and powders by Makovsky et al. ${ }^{20}$ in 1962, and by Derr and Gallagher 21 in 1963. The use of an X-ray source for excitation has proved to be destrable because the filtration of the exciting radiation from the luminescence measurement devices is not necessary, X-ray equipment is common in many laboratories, a vacuum is not needed as in cathodoluminescence, and the method is extremely sensitive. ${ }^{17}$ XEOL has been used in the determination of various rare earths at the sub-ppm level in yttrium, ${ }^{9,10,22-27}$ zirconium, ${ }^{28-30}$ uranium, ${ }^{28,31}$ 1anthanum, 27,32 thorium, 33,34 gadolinium, $9,23,25$ holmium, ${ }^{29}$ calcium, 27 and aluminum. 35 In fact, an analytical tecnhique could be developed for the determination of trace rare earths in any of the 56 elements which serve as a host for XEOL ${ }^{36,37}$ (Figure 1).

Varfous lutetium compounds are effective hosts for trace rare earth luminescence excited by X-radiation $9,36,37$ and therefore, the development of an analytical method using XEOL is a logical answer to the problem of determining rare earth impurities in lutetium. 

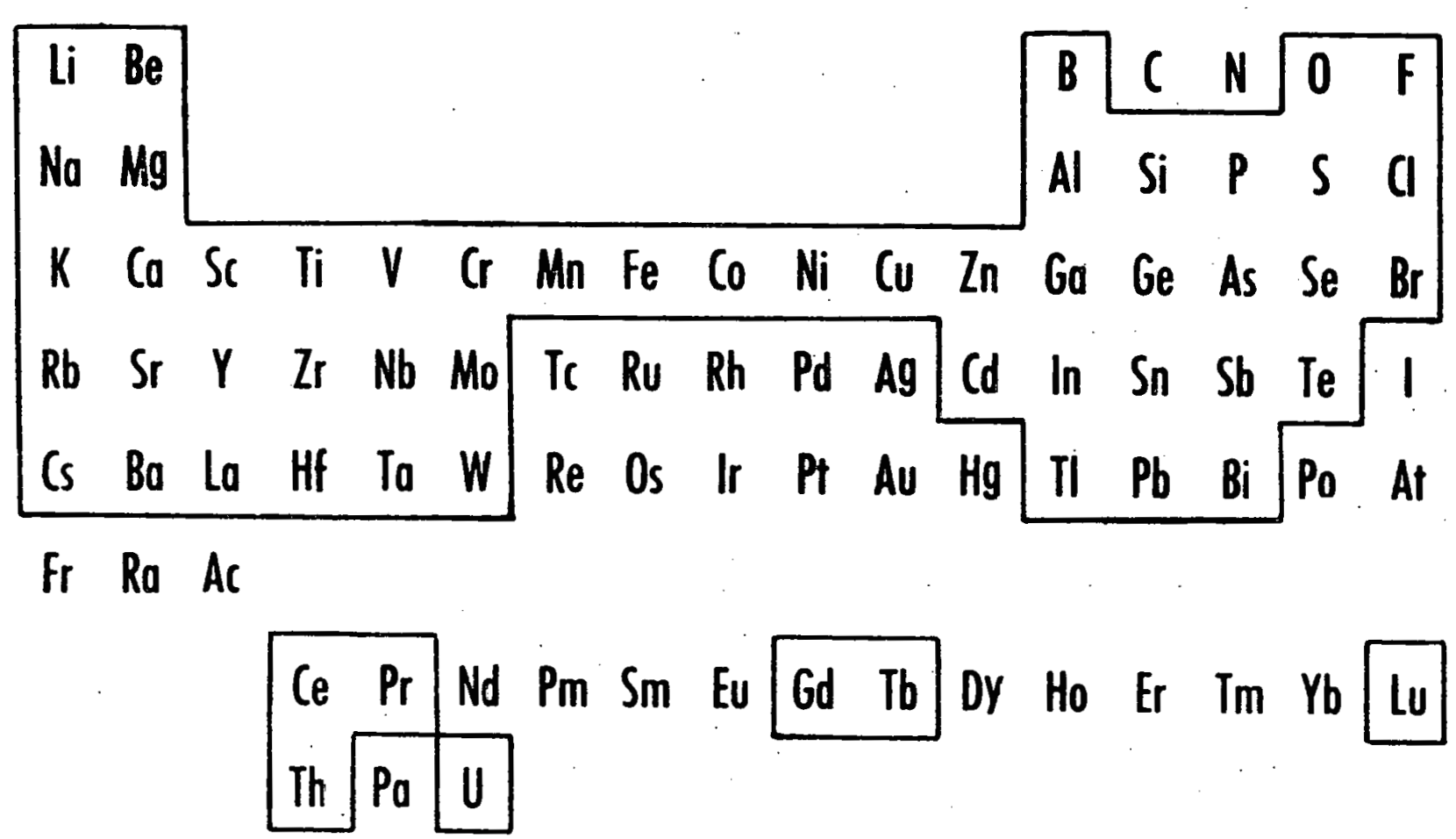

Figure 1. Elements with boxes have been found to form compounds which will support analytically useful $X$-ray excited optical luminescence of trace rare earth impurities ${ }^{36}$ 
THEORY

Not all aspects concerning the process of XEOL in solids are completely understood, but a general mechanism for the luminescence can be deduced from the information and theories presented by several authors. ${ }^{20,36-47}$ An atom upon absorption of an X-ray photon may eject one photoelectron with a certain kinetic energy. If this irradiated atom or Ion is a component of a solid crystal, the photoelectron does not necessarily escape from the crystal, but can impart random amounts of its kinetic energy, ranging from 10 to $30 \mathrm{ev}, 47$ to extranuclear electrons of other atoms in the crystal. These bits of energy can be stored in the crystal as secondary excitants. Therefore, the transferred energy from the photoelectron ejected by just one X-ray photon can produce many secondary excitants.

The production of these secondary excitants can best be explained with the use of the schematic energy diagram of a crystalline insulator or semiconductor shown in Figure 2. Each of the degenerate energy levels of 1solated identical atoms are proliferated into a number of closely spaced energy levels by the effects of the neighboring atoms in a crystal. The energy levels combine to form the energy bands (Figure 2) which exist over the entire crystal not unlike the energy levels of a giant molecule. The valence band in a crystal, the highest energy band which normally contains electrons, has been built up from the valence energy levels of the Individual atoms in the crystal. Solid crystals with a partly filled valence band are electrical conductors and do not luminesce. 36,46 In contrast, electrical insulators and semiconductors have completely filled valence 


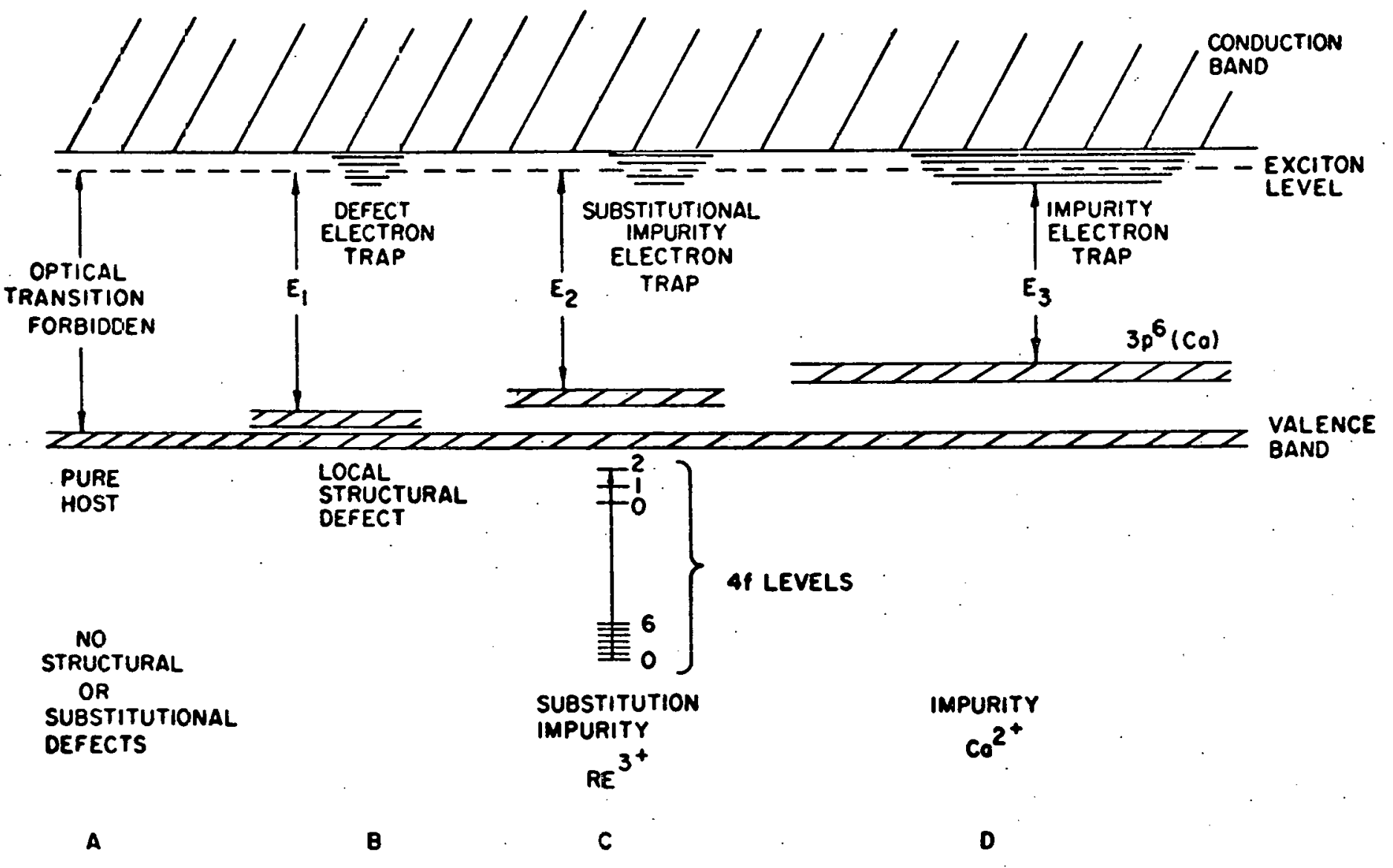

Figure 2. Schematic one-dimensional presentation of energy states in a crystalline insulator or semiconductor 37 
bands and can luminesce. ${ }^{36}$ The lowest ordinarily empty energy band in the crystal is known as the conduction band, and is separated from the valence band by an energy gap which prohibits the promotion and relaxation of electrons under normal conditions.

The secondary excitants created by the ejected photoelectron may exist as elther "free" electrons or excitons. A valence electron may be promoted or excited from the valence band to the conduction band of the crystal leaving a positive hole (an electron deficiency) in the formerly filled valence band. This "free" electron may move about the crystal in the conduction band completely independent of the positive hole. The hole may also move about the crystal, but in a stepwise manner in which the hole is filled by an electron from an adjacent atom resulting in an electron deficiency in the donating atom. The secondary excitant may also exist as an exciton which may be visualized as a positive hole with an exc1ted electron revolving around it rather like a hydrogen atom. ${ }^{46}$ The exciton travels about the crystal as an electron-hole pair in the exciton energy level present just below the conduction band (Figure 2). The difference between the "free" electrons and the exciton 1s not important In the work done for this thesis, but is more important in the mathematical treatment of the energy processes. Recombination of the "free" electron and the hole or relaxation of the exciton in a perfect crystal is a forbidden process and therefore, the secondary excitants have a relatively long lifetime.

Crystal imperfections introduce additional discrete energy levels or bands in the vicinity of the defect. These crystal imperfections can be 
distorted surfaces and Internal structures of the crystal, displaced atoms, omissions, inhomogeneities of composition, or impurities. ${ }^{46}$ The imperfections can contribute levels to the crystal lattice energy scheme which are lower in energy than the conduction band or higher than the valence band ( $B$, Figure 2). The empty energy levels lower than the conduction band can serve to capture the "free" electron or the exciton traveling about the crystal and allow these secondary excitants to return to the valence band with a corresponding release of energy. Impurities present in a crystal can introduce localized filled energy levels above the valence band. These levels act as a positive hole trap in the vicinity of the impurity (Figure 2, C) and at which, in conjunction with the corresponding electron trap, recombination is allowed. The recombination results in the release of energy causing the excitation of the impurity ion. The ion may lose the energy either in non-radiative (heat) and/or radiative (Iuminescence) processes.

The luminescence of most lons in a crystal is broadened by the distortion of the energy levels caused by nearby ions. This diffuse 1.uminescence is of little use analytically, however certain fons in a solid luminesce with analytically useful sharp-Iine spectra because the excited electrons are shielded by electrons in the outer energy shells of the atom. The trivalent rare earth lons are among the elements which behave in this manner because the $4 f$ electrons associated with the luminescence are somewhat protected from the effects of neighboring atoms by the outer $5 s$ and $5 p$ shell electrons. Only lanthanum with an empty $4 f$ electron shell and lutetium with a full $4 \mathrm{f}$ electron shell among the rare earths do not undergo 
this type of luminescence.

A pure rare earth compound may Iuminesce under X-ray excitation, but the Intensity is low since only the rare earth ions near imperfections in the crystal may be excited. However, if these elements are present as impurities in a host, the luminescence is enhanced. 36 The mobility of the secondary excltants and the short lifetime of the excited states of the ions results in repeated excitation of the rare earth ion and therefore In a strong luminescence. ${ }^{36}$ In fact, Leverenz 47 has estimated that one $90 \mathrm{KeV} \mathrm{X}$-ray photon can excite up to 7000 luminescent photons. If only the host and the rare earth impurity are present in the solid and few dislocation traps are present in the crystal, most of the exc1tation will be dissipated by radiative transfer and luminescence will be enhanced. However, non-rare earth impurities present in the solid can act as very efficient electron and positive hole traps (D, Figure 2) and thus cause the loss of excitation energy as heat or as non-rare earth broad band luminescence significantly decreasing the trace rare earth luminescence. The luminescing trace impurities are known as "activators" in matrices or hosts called "absorbers." 42 Th1s is an appropriate designation because the activator cannot directly absorb enough energy from the incident $X$-ray beam to produce the intense luminescence observed, $22,36,48$ but, as described in the mechanism set forth above, the host. "absorbs" the energy and transmits the energy to the "activator." 
EXPERIMENTAL APPARATUS AND PROCEDURES

Apparatus

A schematic diagram of the apparatus used in this investigation is shown in Figure 3, and the lead-lined sample holder ${ }^{49}$ that allowed facile, safe, and reproducible exchange of the solid samples without the necessity of discontinuing the $X-r a y$ power is shown in Figure 4. The components of this experimental facility and the conditions of operation are delineated in Table 1.

Phosphor Research

Several lutetium compounds support trace rare earth luminescence upon excitation by $X$-radiation, $9,36,37$ but $x$-ray excited optical luminescent spectra of holmium, erbium, thulium, or ytterbium as impurities have not been reported in any lutetium host. Therefore, an investigation was necessary to determine the spectra of these impurities in possible lutetium hosts and, from these data determine the best lutetium host for analytical use. The number of possible XEOL hosts is limited only by the many insulators or semiconductors which can be prepared containing lutetium. On1y oxygen dominated compounds were used in this study because Palilla ${ }^{48}$ and Poluéktov et al. 50 have found that these phosphors are generally the most sensitive hosts for luminescence of trace rare earths excited by either UV light or X-radiation.

The effective oxygen dominated crystalline hosts have been classified by Johnson ${ }^{51}$ and by DeKalb et al. ${ }^{36}$ into four general types of phosphors consisting of the simple oxides $\left(M_{x} 0_{y}\right)$, binary oxides $\left(M_{x} A_{y} 0_{z}\right)$, ternary 


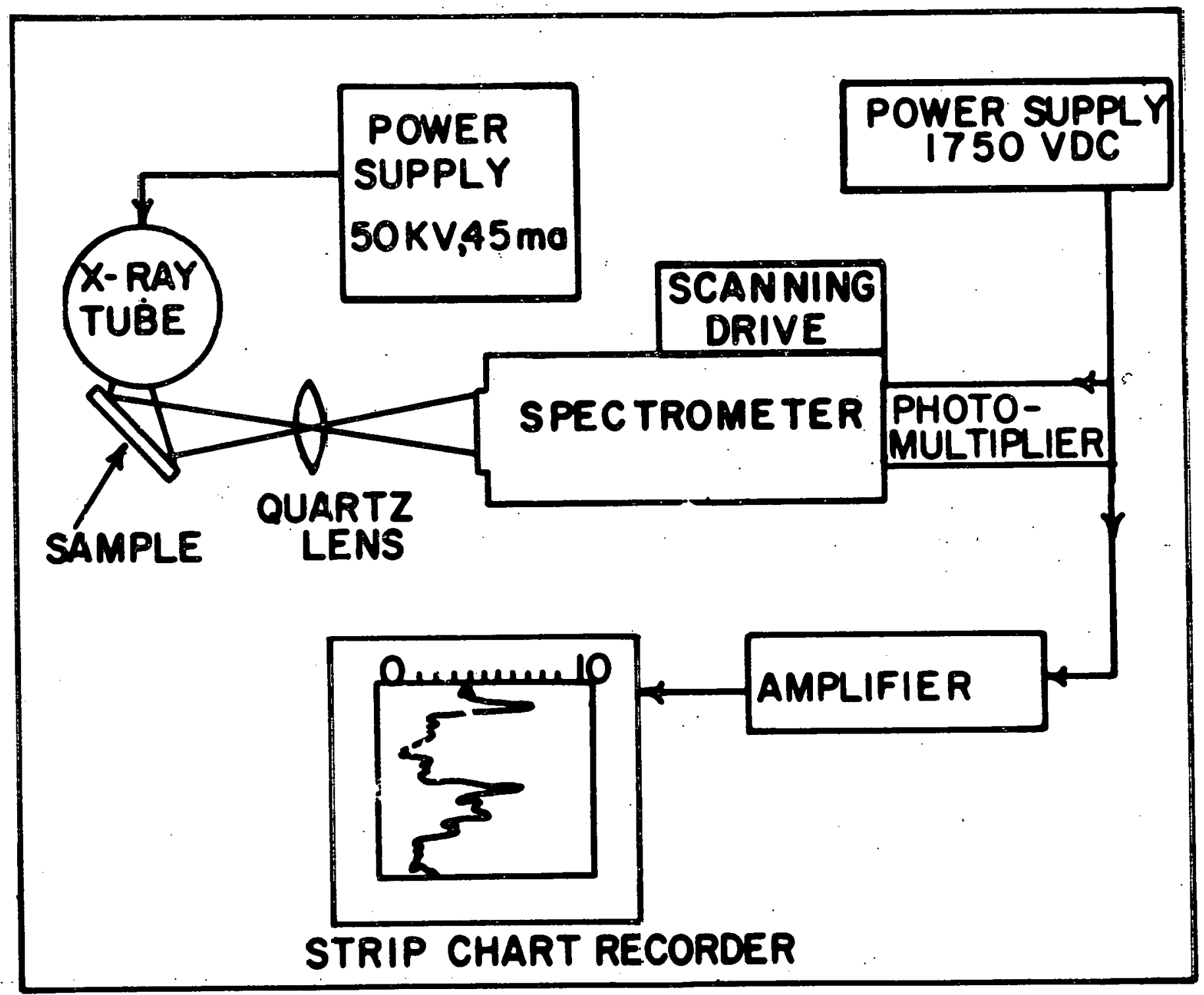

Figure 3. A schematic diagram of the experimental facility for observing XEOL spectra 


\section{THIS PAGE \\ WAS INTENTIONALLY \\ LEFT BLANK}


Figure 4. A sample chamber provides for the completely safe exchange of samples even though the $X$-ray tube (a) conzinues in operation at full power. During activation of the sample in this chamber, a sma11 access door (b) is blocked in the alosed position by a large lever ic). To exchange samples, the lever and an attached shutter (d) are rotated so that the X-ray beam is completely interrupted before the door can be raised. The sample is accurately and reproductbly positioned at an angle of $45^{\circ}$ to the incident $X$-ray beam through the use of a vee-way mounting block (e) and mating sample holder (f) 49 


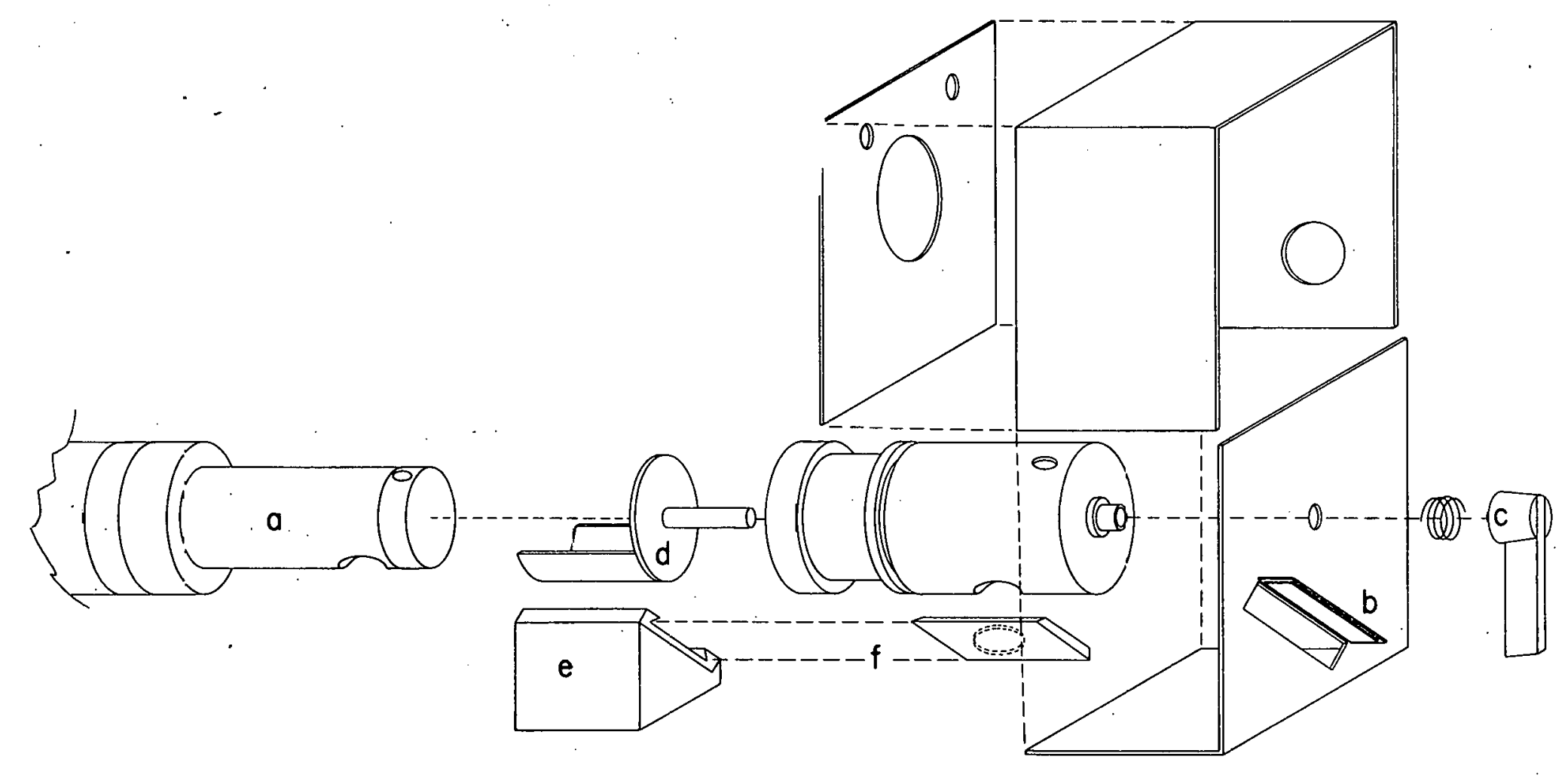


Table 1. Experimental facilities and operating conditions

\begin{tabular}{|c|c|}
\hline Component & Description and Operating Conditions \\
\hline $\mathrm{X}$-ray Power Supply & $\begin{array}{l}\text { Norelco Model } 12043 \text { operated at } 50 \mathrm{kv} \text {, } \\
45 \mathrm{~mA}\end{array}$ \\
\hline $\mathrm{X}$-ray Tube & $\begin{array}{l}\text { Machlett } \text { OEG } 50 \text { tungsten target tube } \\
\text { emitting X-rays at } \sim 0.02 \mathrm{~nm}\end{array}$ \\
\hline External Optics & $\begin{array}{l}3.0 \mathrm{~cm} \text { diameter spherical quartz lens. } \\
\text { A Corning H.R. } 2-63600 \mathrm{~nm} \text { cut-off filter } \\
\text { was used to eliminate the second order. }\end{array}$ \\
\hline Spectrometer & $\begin{array}{l}\text { Jarrell-Ash Model } 82-410,0.25 \text { meter } \\
\text { Ebert mount with } 590 \text { grooves/mm grating } \\
\text { blazed for } 1.2 \mu \text {. A scanning speed of } \\
40 \mathrm{~nm} / \mathrm{minute} \text { was used for most determina- } \\
\text { tions. }\end{array}$ \\
\hline Slits & $250 \mu$ fixed slits \\
\hline Photomultiplier & $\begin{array}{l}\text { Amperex Model } 150 \text { CVP PMT, S-1 response } \\
\text { tube mounted in a dry ice cooled enclosure } \\
\text { (Photometric Instrument Model 77) to cool } \\
\text { the photomultier to }-60^{\circ} \mathrm{C} \text { decreasing the } \\
\text { dark current. }\end{array}$ \\
\hline Photomultiplier Power Supply & $\begin{array}{l}\text { New Jersey Electronics Corporation Model } \\
\text { S- } 325 \text { with } 500-2500 \mathrm{~V}, 0-10 \mathrm{~mA} \text { capabilities. } \\
\text { The voltage was adjusted between } 1000 \\
\text { and } 1600 \mathrm{~V} \text {. }\end{array}$ \\
\hline Photocurrent Amplifier & $\begin{array}{l}\text { Keithley Model } 1417 \text { Picoammeter, full scale } \\
\text { ranges } 1 \times 10^{-9} \text { A to } 3 \times 10^{-8} \text { A were used. }\end{array}$ \\
\hline Recorder & $\begin{array}{l}\text { Leeds and Northrup Speedomax } G \text { Model } s \\
\text { millivolt recorder using two pens with one } \\
\text { pen } 1 / 10 \text { as sensitive as the other. }\end{array}$ \\
\hline
\end{tabular}


oxides $\left(M_{x} A_{y} B_{y}, O_{z}\right)$, and oxyhalides $(M O C)$. The symbol $M$ in each general formula indicates an element from group IIA, IIIA, IIIB, or IVB of the periodic chart; however, in this study, only phosphors prepared from the actinide or lanthanide elements were considered. The letters $A$ and $B$ are efther aluminum, phosphorous, sulfur, tellurium, tungsten, or vanadium and In addition $B$ may be an alkali element. Finally, C represents one of the halogen elements.

The simple oxides have been used extensively as trace rare earth activated phosphors in the analytical chemistry of many host materials. Holmium, erbium, and thulium luminescence has been reported in $\mathrm{ThO}_{2}{ }^{52}$ and $\mathrm{Y}_{2} \mathrm{O}_{3}{ }^{14,53}$ excited by UV 1 ight and in $\mathrm{ThO}_{2},{ }^{34} \mathrm{Gd}_{2} \mathrm{O}_{3}, 9,23,54 \mathrm{La}_{2} \mathrm{O}_{3}, 32$ and $\mathrm{Y}_{2} \mathrm{O}_{3}{ }^{9,23,54}$ excited by $\mathrm{X}$-radiation. Ytterblum Iumfnescence has been found in $\mathrm{Gd}_{2} \mathrm{O}_{3}{ }^{9,23,54}$ and $\mathrm{Y}_{2} \mathrm{O}_{3}{ }^{9,23,26,54}$ under $\mathrm{X}$-ray excitation only in the near infrared region of the spectrum from $980.0 \mathrm{~nm}$ to $1040.0 \mathrm{~nm}$. Therefore, the the presence of $\mathrm{X}$-ray excited luminescence of the analytes in a varlety of simple oxides is well established. In addition, $\mathrm{Lu}_{2} \mathrm{O}_{3}$ phosphors have served as hosts for the luminescence of a varlety of rare earths, not including the elements of concern in this study, excited by $X-r^{2} y^{9,36}$ or $\mathrm{UV}^{55}$ photons. Thus, $\mathrm{Lu}_{2} \mathrm{O}_{3}$ would seem to be an excellent host-for X-ray exc1ted luminescence of trace amounts of holmium, erbium, thulium, and ytterblum. Several classes of binary oxide hosts exhibit trace rare earth liminescence excited either by UV or X-ray photons. These hosts include the aluminum garnets $\left(\mathrm{M}_{3} \mathrm{Al}_{5} \mathrm{O}_{12}\right)$, the phosphates $\left(\mathrm{MPO}_{4}\right)$, the oxysulfides $\left(\mathrm{M}_{2} \mathrm{O}_{2} \mathrm{~S}\right)$, the tellurates $\left(\mathrm{M}_{2} \mathrm{TeO}_{4}\right)$, the vanadates $\left(\mathrm{MVO}_{4}\right)$, and the tungstates $\left(\mathrm{MWO}_{4}\right)$. Some of these hosts can be Immediately eliminated as posstble 
analytical phosphors because the preparations are too difficult or lengthy (tellurates ${ }^{56}$ and garnets ${ }^{22}$ ) for routine analytical determinations. The tungstate hosts support luminescence which is much less Intense than most of the other phosphors in this group 50 and thus they were also eliminated.

Phosphates have been used effectively as hosts for erbium and thulium luminescence in $\mathrm{LaPO}_{4}, \mathrm{GdPO}_{4}$, and $\mathrm{YPO}_{4}$ excited by ultravlolet 1 ight 57 and In $\mathrm{YPO}_{4}{ }^{24}$ by X-ray excitation. $\mathrm{A} \mathrm{LuPO}_{4}$ host could possibly be a good matrix for XEOL.

Trace rare earth luminescence excited by $\mathrm{X}$-radiation has been reported in the oxysulfides of yttrium, ${ }^{36}$ lanthanum ${ }^{58}$ and gadolinium. ${ }^{58}$ Lutetium oxysulfide could also be an efficient host.

Rather extensive work has been done using the vanadates as hosts for UV and X-ray excited trace luminescence. Several of them, including lutetium vanadate, ${ }^{16,59}$ have been recommended as excellent hosts using UV excitation. ${ }^{48,60}$ The trace luminescence in the vanadate is much more intense than In the oxides or phosphates using either $U V^{61,62}$ or $X-r^{24}$ excitation. Holmium, erbium, and thulium UV excited luminescence has been reported in $\mathrm{GdVO}_{4},{ }^{59-61} \mathrm{YvO}_{4}, 59,60,62 \mathrm{LaVO}_{4},{ }^{59,60} \mathrm{ScVO}_{4}{ }^{63}$ and $\mathrm{LuVO}_{4}{ }^{16,59}$. In addition, UV excited ytterbium luminescence, present only in the 900.0 $\mathrm{nm}$ to $1000.0 \mathrm{~nm}$ wave length range, was found in $\mathrm{ScVO}_{4},{ }^{63} \mathrm{GdVO}_{4}{ }^{61}$ and LuVo $_{4} \cdot 16$ All four analytes Iuminesce as trace impurities in YVO 4 under X-ray excitation ${ }^{24}$ and therefore, lutetium vanadate would seem to be a possible host.

The ternary oxides contain non-rare earth cations in addition to the rare earth element $\left[\mathrm{e} . \mathrm{g} \cdot \mathrm{LIY}\left(\mathrm{WO}_{4}\right)_{2}\right]$. Phosphors of this type were not 
studied because the trace holmium, erbium, thulium, and ytterbium luminescence is much less intense in this type of host than in hosts in which only one rare earth cation is present as a major constituent. 64

Several rare earth oxyhalides have been shown to support trace luminescence using $x$-ray excitation ${ }^{36}$ or UV excltation. ${ }^{50}$ The oxyhalides are not useful analytically because these compounds are mixtures of the halide and the oxide and not present as the oxyhalide "MOC."36 The exact proportions of the mixture are very hard to reproduce and consequently the luminescence would change drastically from sample to sample.

The spectra of trace amounts of holmium, erbium, thulium, and ytterbium in lutetium oxide, oxysulfide, phosphate and vanadate hosts were obtained by preparing several samples of the host "doped" with various amounts of each rare earth impurity. Each "doped" sample was prepared by dissolving a portion of the original lutetium oxide base material in dilute nitric acid and then adding the desired amount of the rare earth dopant solution prepared from a nitric acid dissolution of the pure metal. This mixture was evaporated to dryness forming solid lutetium nitrate containing the dopant rare earths. The nitrate was heated at $600^{\circ} \mathrm{C}$ until the evolution of nitrogen dioxide ended, signalling the conversion of the nitrate to the oxide. 65,66 The complete decomposition of the nitrate: to the oxide and the incorporation of the dopant in the lutetium oxide powder was accomplished by the ignition of the solid at $1200^{\circ} \mathrm{C}$ for one hour. The resulting lutetium oxide was used to prepare all the hosts doped with various amounts of the rare earth analytes. The dissolving, drying, and firing procedure is necessary to ensure that the rare earth dopants are in 
the lattice structure of the crystalline host, a simple mechanical mixing will not suffice in this regard. 23

\section{Lutetium oxide}

To prepare the lutetium oxide host, 0.25 grams of the base lutetium oxide was ground in an agate mortar and ignited at $1200^{\circ} \mathrm{C}$ for one hour 24 to incorporate the dopant rare earths in the lattice. 67

\section{Lutetium oxysulfide}

The procedure described by Royce and Thomsen ${ }^{68}$ was followed in the preparation of the oxysulfide based host. This method consists of grinding $0.26 \mathrm{~g} \mathrm{Lu}_{2} \mathrm{O}_{3}, 0.08 \mathrm{~g} \mathrm{Na}_{2} \mathrm{CO}_{3}, 0.08 \mathrm{~g} \mathrm{Na}_{2} \mathrm{SO}_{4}$, and $0.08 \mathrm{~g}$ elemental sulfur in an agate mortar and igniting the mixture for one hour at $1200^{\circ} \mathrm{C}$ in a covered porcelain crucible. The solid was washed with water to extract the residual sodium compounds and the oxysulfide was collected by filtration and drying. The $\mathrm{Na}_{2} \mathrm{CO}_{3}, \mathrm{~S}$, and $\mathrm{Na}_{2} \mathrm{SO}_{4}$ were added because the sodium carbonate reacts with the sulfur at high temperatures to produce a melt of sodium polysulfides and sulfate which reacts with the $\mathrm{Lu}_{2} \mathrm{O}_{3}$ to form the oxysulfide.

\section{Lutetium phosphate}

The lutetium phosphate host was prepared according to the method outlined by D'Silva and Fassel ${ }^{24}$ for yttrium phosphate. The corresponding 1.11tetium phosphate was prepared by grinding $0.25 \mathrm{~g} \mathrm{Lu}_{2} \mathrm{O}_{3}, 0.18 \mathrm{~g}\left(\mathrm{NH}_{4}\right)_{2} \mathrm{HPO}_{4}$, and $0.06 \mathrm{~g} \mathrm{Na}{ }_{4} \mathrm{P}_{2} \mathrm{O}_{7} \cdot 10 \mathrm{H}_{2} \mathrm{O}$ in a mortar, firing the mixture for five minutes at $600^{\circ} \mathrm{C}$, and igniting at $1200^{\circ} \mathrm{C}$ for one hour. At $600^{\circ} \mathrm{C}$, the $\left(\mathrm{NH}_{4}\right)_{2} \mathrm{HPO}_{4}$ decomposes into ammonia and phosphoric acid. ${ }^{69}$ Thephosphoric acid reacts 
with the lutetium oxide to form lutetium phosphate and water. The small amount of $\mathrm{Na}_{4} \mathrm{P}_{2} \mathrm{O}_{7} \cdot 10 \mathrm{H}_{2} \mathrm{O}$ in the mixture serves as a crystallizing agent. 24,70

\section{Lutetium vanadate}

The vanadate host was prepared by mixing $0.26 \mathrm{~g} \mathrm{Lu}_{2} \mathrm{O}_{3}$ and $0.08 \mathrm{~g}$ $\mathrm{NH}_{4} \mathrm{VO}_{3}$ in a mortar according to the method described by D'Silva and Fasse1. ${ }^{24}$ The mixture was 1gnited at $600^{\circ} \mathrm{C}$, ground again, and ignited at $1200^{\circ} \mathrm{C}$ for one hour. The heating of the mixture causes the decomposition of $\mathrm{NH}_{4} \mathrm{VO}_{3}$ to $\mathrm{V}_{2} \mathrm{O}_{5}{ }^{71}$ which reacts with the lutetium oxide to form the vanadate. 60

The determination of the luminescence of the rare earth analytes in the hosts was done by preparing a series of samples of each of the hosts. Each host in a series was doped with one of the rare earths at concentrations ranging from five to $100 \mathrm{ppm}$. Therefore, by correlating the increased intensity of a luminescent line with the rare earth added, one can determine the spectral lines of the rare earths in each host.

Two examples of the XEOL spectra of the analytes in each of the four hosts shown on Figures 5,6,7, and 8 were prepared from (1) "pure" lutetium oxide containing $10 \mathrm{ppm}$ residual ytterbium and (2) the same "pure" oxide doped with $50 \mathrm{ppm}$ holmium, $10 \mathrm{ppm}$ erbium, and $5 \mathrm{ppm}$ thulium in addition to the residual ytterbium.

The oxysulfide (Figure 5) is an unsatisfactory host because the holmium, erbium, and thulium lines interfere with each other. The same problem that eliminated the oxysulfide host as a posstbility also eliminated the oxide host as wcll (Figure 6). Discrcte holmium or thulium lines 


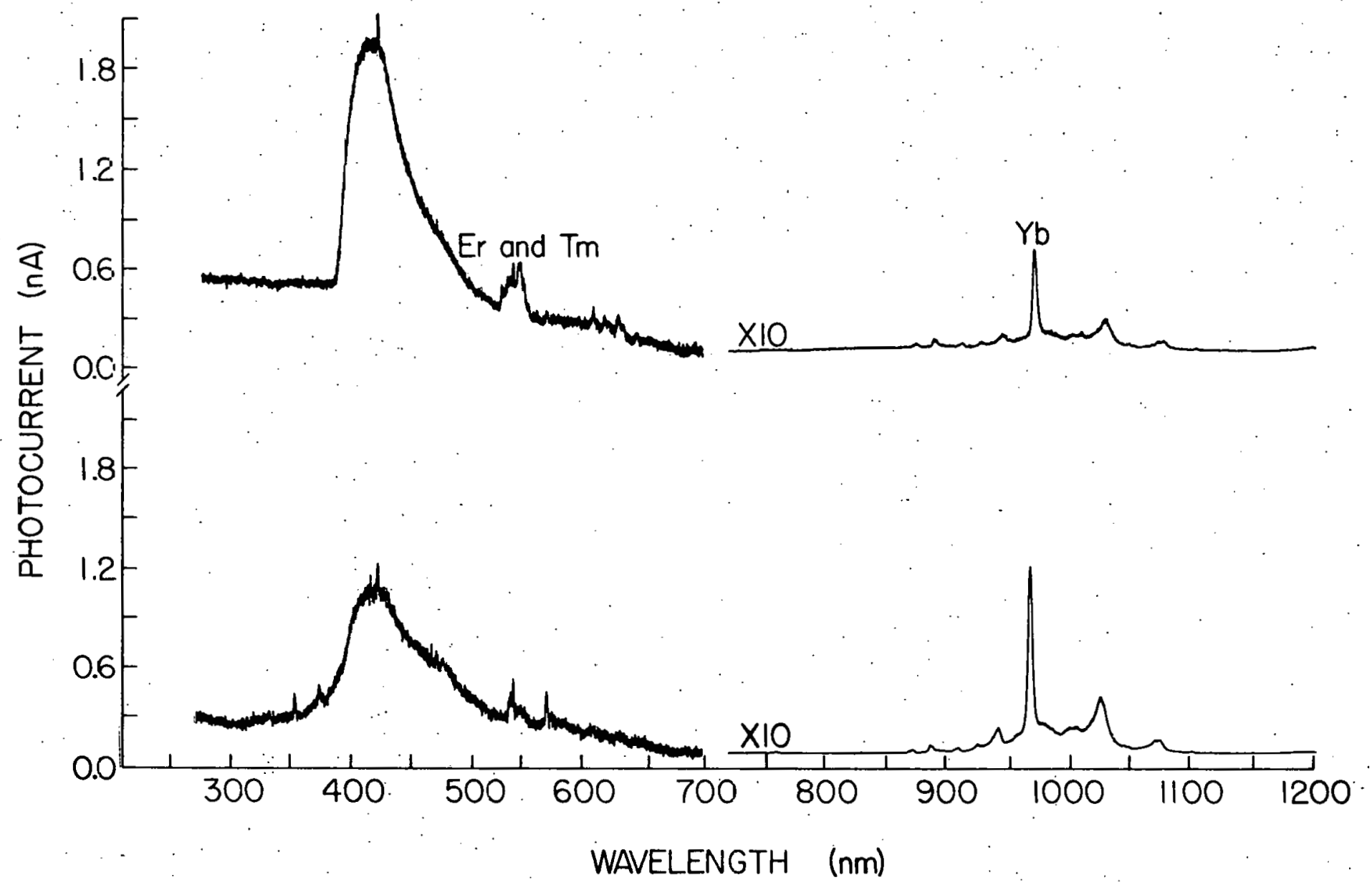

เ

Figure 5. XEOL spectra of $\mathrm{Lu}_{2} \mathrm{O}_{2} \mathrm{~S}$ host (lower spectrum) containing $10 \mathrm{ppm}$ Yb and the same host with $50 \mathrm{ppm}$ Ho, $10^{2} \mathrm{ppm} \mathrm{Er}$, and $5 \mathrm{ppm} \mathrm{Tm}$ added 


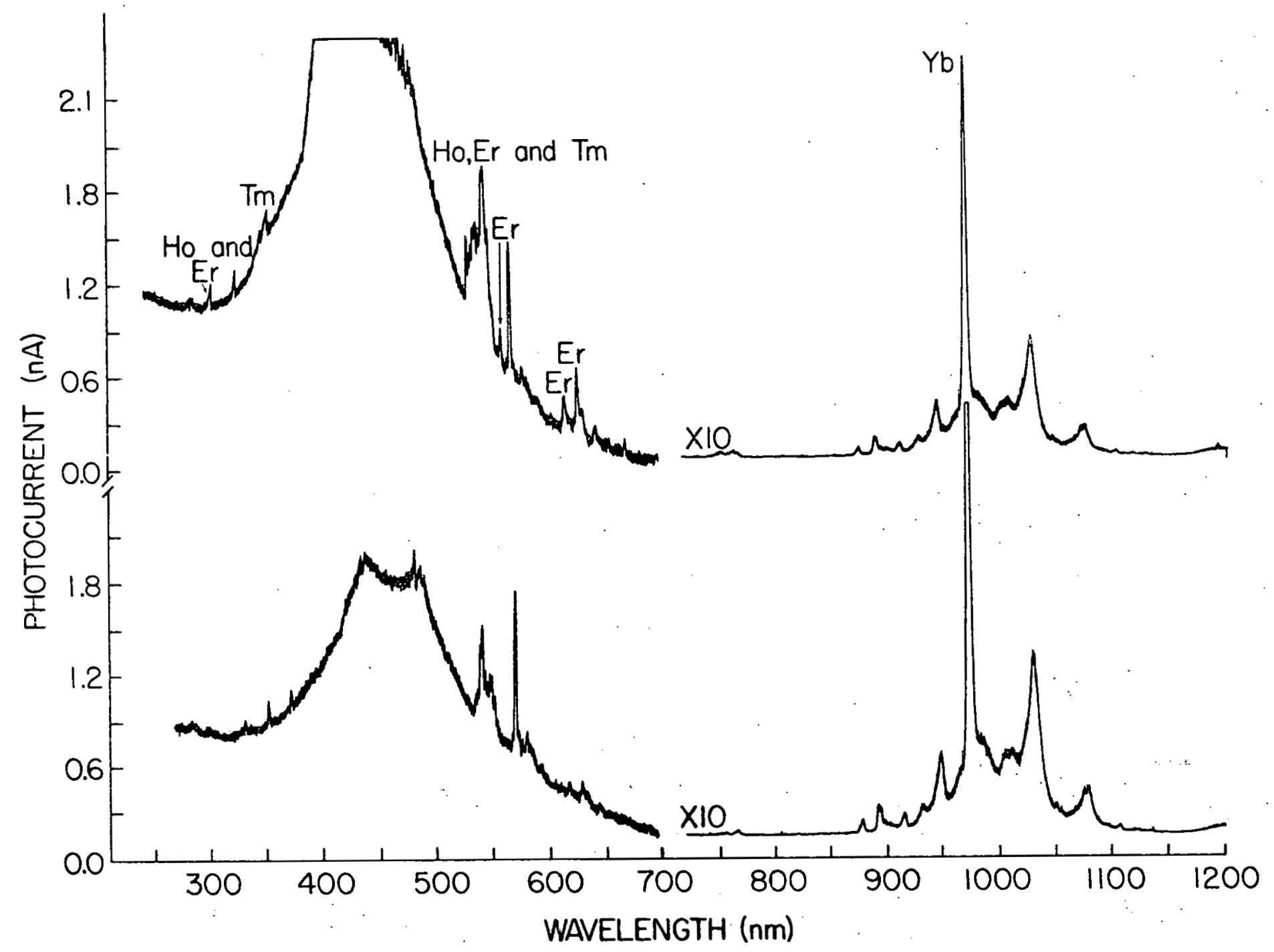

Figure 6. XEDL spectra of $\mathrm{Lu}_{2} \mathrm{O}_{3}$ host (lower spectrum) containing $10 \mathrm{ppm} \mathrm{Yb}$ and the same host with $50 \mathrm{ppm}$ llo, $10 \mathrm{ppm} \mathrm{Er}$, and 5 ppm Tm added 


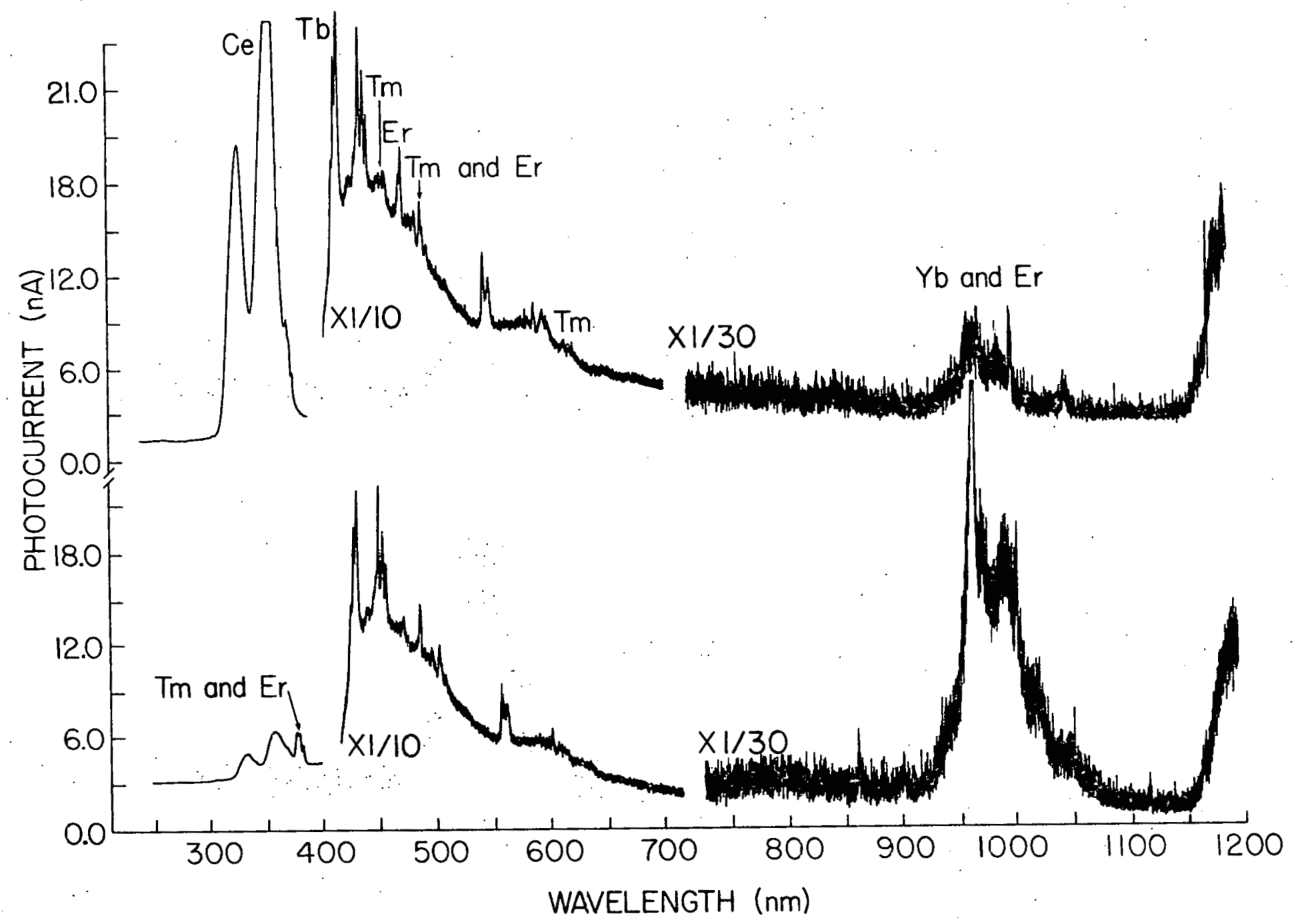

Figure 7. XEOL spectra of $\mathrm{LuPO}_{4}$ host (lower spectrum) containing $10 \mathrm{ppm} \mathrm{Yb}$ and the same host with $50 \mathrm{ppm} \mathrm{Ho,} 10 \mathrm{ppm} \mathrm{Er}$, and $5 \mathrm{ppm} \mathrm{Tm}$ added 


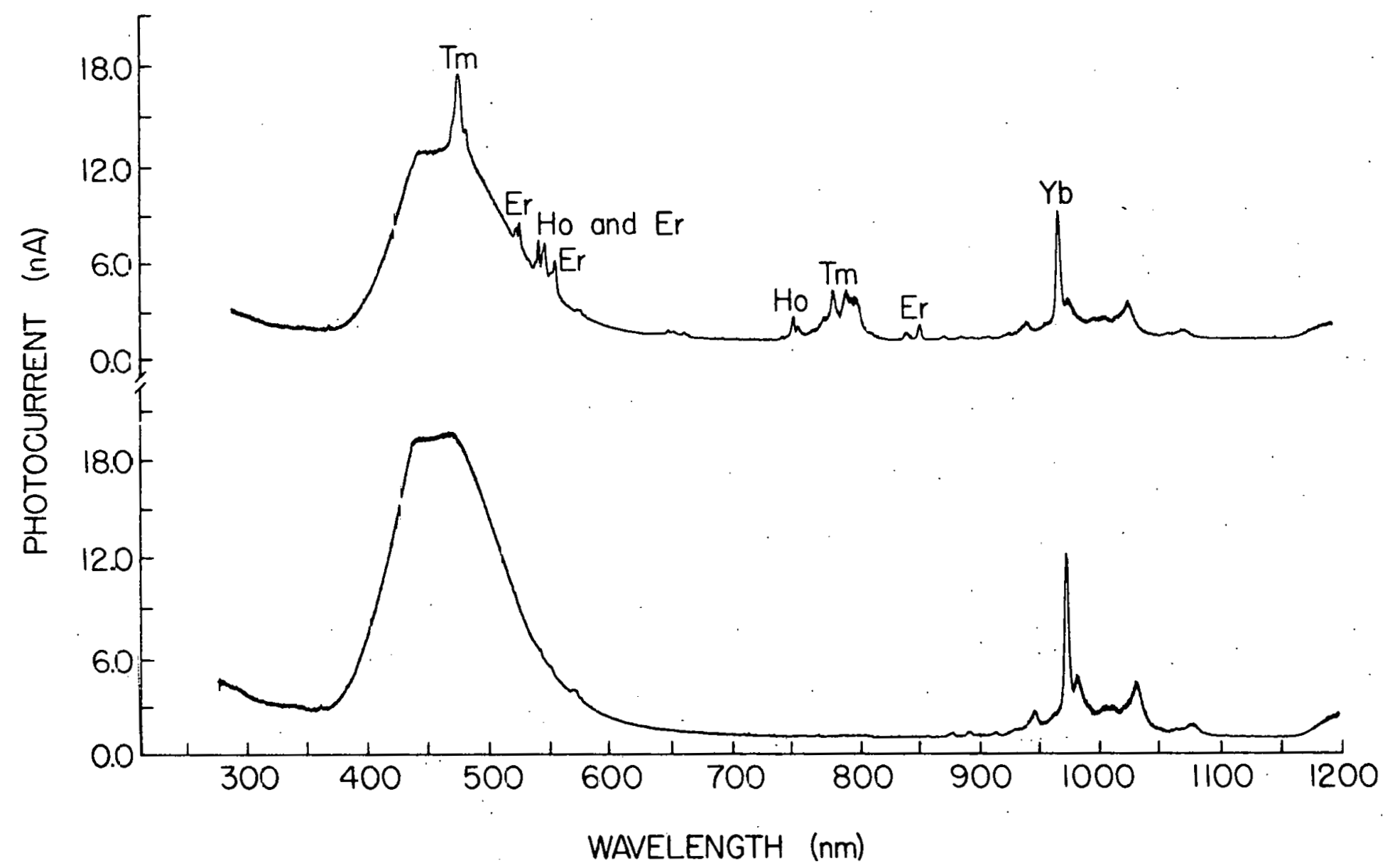

Figure 8. XEOL spectra of LuVO, host (lower spectrum) containing $10 \mathrm{ppm} Y \mathrm{~b}$ and the same host with $50 \mathrm{ppm}$ Ho, $.10 \mathrm{ppm} \mathrm{Er}$, and $5 \mathrm{ppm} \mathrm{Tm}$ added 
unencumbered by interferences are not present in the luminescence of the oxide host. The ytterbium luminescence, however, is more intense in the oxide than in any other host and therefore, the oxide could serve as a sensitive host for the determination of ytterbium in lutetium.

The phosphate is also not a good choice because the rare earth luminescence (especially thulium and ytterbium, Figure 7) is very weak and in addition, no holmium line was intense enough to be seen with the instrumentation described above. The strength of the cerium and terbium luminescence could be used in very sensitive analytical determinations of these elements; however, the cerium determinations might not be practical. The amount of cerium present is identical in both the blank and the doped sample, but a gross disparity in the luminescence of the element in the two hosts is present. This could indicate an energy transfer between one or more of the dopants and the residual cerium which would make analytical determinations difficult.

A comparison of the four sets of spectra indicates that only the vanadate is applicable to the determination of holmium, erbium, thulium, and ytterbium present in lutetium. It is a good host because the holmium, erbium, and thulium luminescence is more intense in the vanadate (Figure 8) than in any of the other hosts and because, in the near-infrared region, the analyte lines are free from interferences. Also in the near-infrared, no broad band luminescence is present as in the visible region of the spectrum and thus the measurement of the peak intensities is much easier.

Finally, the close proximity of the analytically useful holmium, erbium, and thulium lines to the ytterblum line (which is always present 
using just one filter system and photomultiplier tube. The entire scan of the four 1 ines from $1000 \mathrm{~nm}$ to $650 \mathrm{~nm}$ takes only ten minutes. . The lines used for the determinations and the possible energy transitions are shown in Table 2. An example of an XEOL spectrum of a sample containing $10 \mathrm{ppm}$ of each impurity is shown in Figure 9.

\section{Selection of the Internal Reference Element}

Several problems encountered in XEOL analysis concern the varlance of the analyte ine intensities with a variety of factors including the preparation and handling of the phosphor and the non-rare earth impurities present in each sample. The sample ignition temperature and time can cause gross changes in rare earth luminescence. Also, short term changes in Ine intensities will occur in samples of the same composition seemingly prepared identically because of inconsistencies of crystal formation and the degree of absorption of $\mathrm{CO}_{2}$ and $\mathrm{H}_{2} \mathrm{O}$ by the host. 49 These factors can be minimized by careful control of the experimental conditions, however the chemical nature and concentration of non-rare earth 1mpurfties in the host cause analytical line enhancement or depression which is impossible to reproduce in different samples. This difficulty would seem to make analytical measurements impractical; however, DeKalb et al. ${ }^{49}$ have shown that the luminescence of individual rare earth elements in a phosphor are of ten affected identically by the factors causing enhancement or depression. This fact suggests the use of the internal reference method, 72 which is particularly useful in XEOL analyses $23,30,31,34$ to correct for the changes in the luminescence intensities.

Several properties define a good internal reference for an XEOL 
Table 2. Analytical lines and possible energy transitions

Element Analytical Line (nm) Possible Energy Transition ${ }^{27}$

$\begin{array}{lcc}\text { Holmium } & 761.0 & { }^{5} \mathrm{I}_{5} \rightarrow{ }^{5} \mathrm{I}_{8} \\ \text { Erbium } & 866.0 & { }^{4} \mathrm{~S}_{3 / 2} \rightarrow{ }^{4} \mathrm{I}_{13 / 2} \\ \text { Thulium } & 805.5 & { }^{1} \mathrm{G}_{4}+{ }^{3} \mathrm{H}_{5} \\ \text { Ytterbium } & 991.0 & { }^{2} \mathrm{~F}_{5 / 2}+{ }^{2} \mathrm{~F}_{7 / 2}\end{array}$




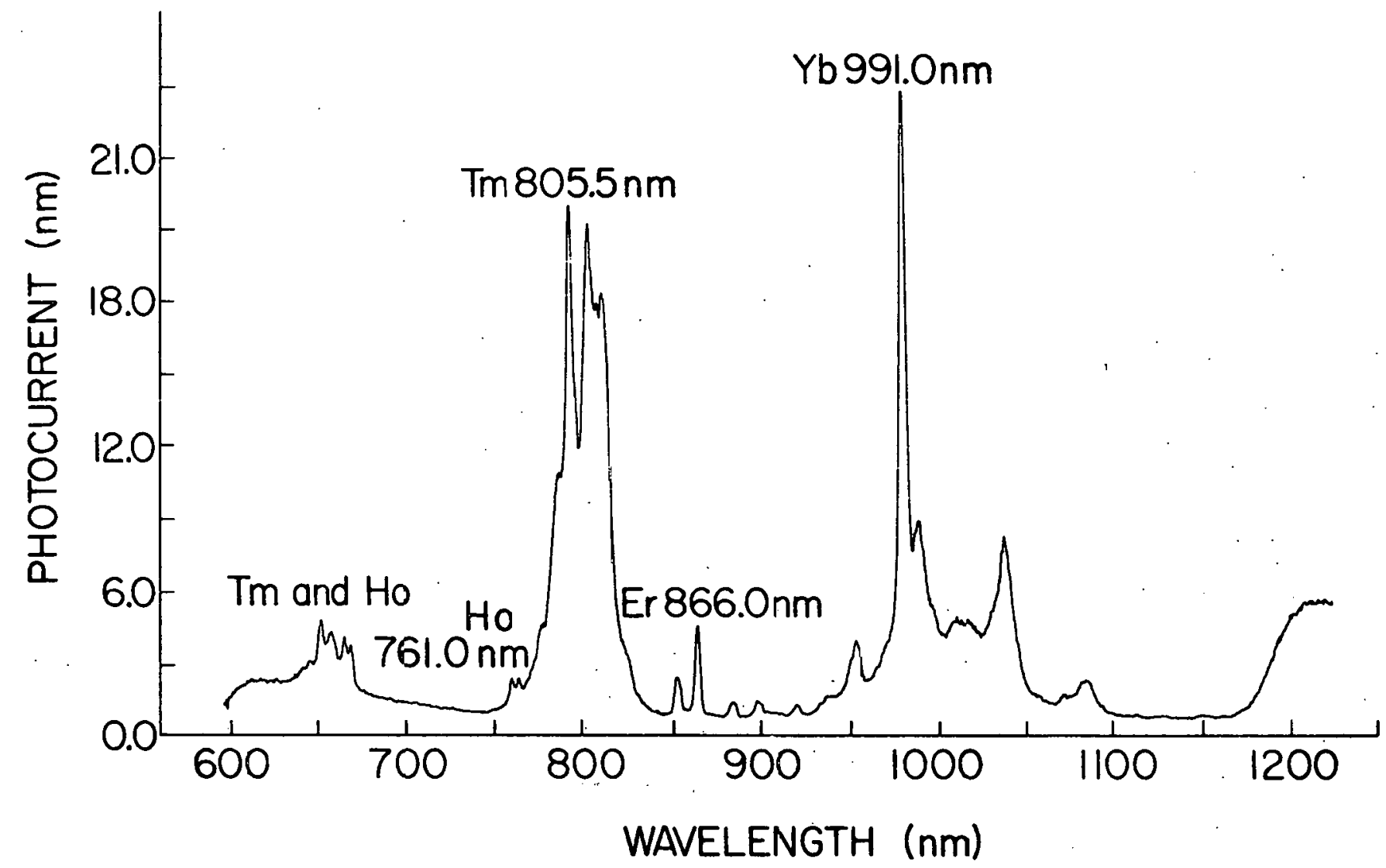
Figure 9. XEOI spectrum of LuVO doped with $10 \mathrm{ppm}$ each of holmium, erbium,
thulium, and ytterbium 
analytical technique. Obviously, the element must have XEOL spectral lines which do not interfere with the spectral lines of the elements being determined. In addition, the internal reference 1ines and the analytical lines must react simflarly to the factors causing enhancement or depression of the rare earth intensities. The amount of the internal reference added to the sample should greatly exceed the residual amount of the reference element present in a normal sample so that any varlations of the residual amount does little to change the total effective concentration and thus the luminescence of the internal reference. However, the amount of reference element added should be much less than $100 \mathrm{ppm}$ because interelement effects between the analyte and the reference present at this level can cause significant changes in the rare earth analyte luminescence. 9. Therefore, combining these two preceding factors, the reference element should luminesce strongly enough so that only a small amount of the reference is necessary to produce a measurable line intensity, and yet the element should not be a common constituent in the "pure" lutetium so that the amount of reference added overwhelms any residual reference element prescnt.

The rare earths praseodymium, neodymium, europium, and samarium were Investigated as possible internal references, but only samarium was found to be acceptable. The samarium Iines do not interfere with any of the analyte lines and are quite intense even at the $10 \mathrm{ppm}$ level. This concentration of samarium added to the host is large enough to "swamp" by several orders of magnitude and residual samarium present in most lutetium samples because of the efficient chemical separation of samarium from 
lutetium. ${ }^{1}$ The $723.0 \mathrm{~nm}$ samarium line (possible energy transition $\left.{ }^{4} \mathrm{G}_{5 / 2}+{ }^{6} \mathrm{H}_{9 / 2}\right){ }^{27}$ was used as the internal reference.

The other rare earths studied as possible internal references in this experiment were found to interfere with one or more of the analyte lines. The XEOL spectra of these elements in the 600 to $1200 \mathrm{~nm}$ region are quite Intense and therefore could produce a sensitive analytical method for the. determination of europlum, praseodymium, and neodymium in lutetium by XEOL .

Finally, and perhaps most critfcally, the samarlum must compensate for the enhancement or depression caused by common impurities present in a lutetium oxide sample. Figures $10,11,12$ and 13 show the results of an experiment in which five lutetium vanadate phosphors had been doped with excessive amounts (up to $400 \mathrm{ppm}$ ) of several common impurities. The coefficient of variation for the relative intensity of the analytical ine for each element in the flve doped samples and a blank is given below:

$\begin{array}{ll}\text { Holmium } & 17 \% \\ \text { Erbium } & 19 \% \\ \text { Thulium } & 19 \% \\ \text { Ytterbium } & 20 \%\end{array}$

In contrast, the coefficient of variation for the intensity ratio of each element to samarium is:

$\begin{array}{ll}\text { Holmium } & 5 \% \\ \text { Erbium } & 2 \% \\ \text { Thulium } & 3 \% \\ \text { Ytterbium } & 3 \%\end{array}$


THIS PAGE

WAS INTENTIONALLY

LEFT BLANK 
Figure 10. Effect of Internal standaridization in sompensating for the variation of the Ho luminescence upon tize addition of nonrare earth impurities. All sampies contain $33 \mathrm{ppm}$ Ho. Sample I, no additions; Sample II, $100 \mathrm{ppm} \mathrm{Na;} \mathrm{Sample} \mathrm{III,} 100 \mathrm{ppm} \mathrm{Ca;}$ Sample IV, IJO ppm Fe; Sample V, $100 \mathrm{ppI} \mathrm{Al;} \mathrm{Sample} \mathrm{VI,} 100 \mathrm{ppm}$ each $\mathrm{Na}, \mathrm{Ca}, \mathrm{Ze}$, and $\mathrm{Al}$ 


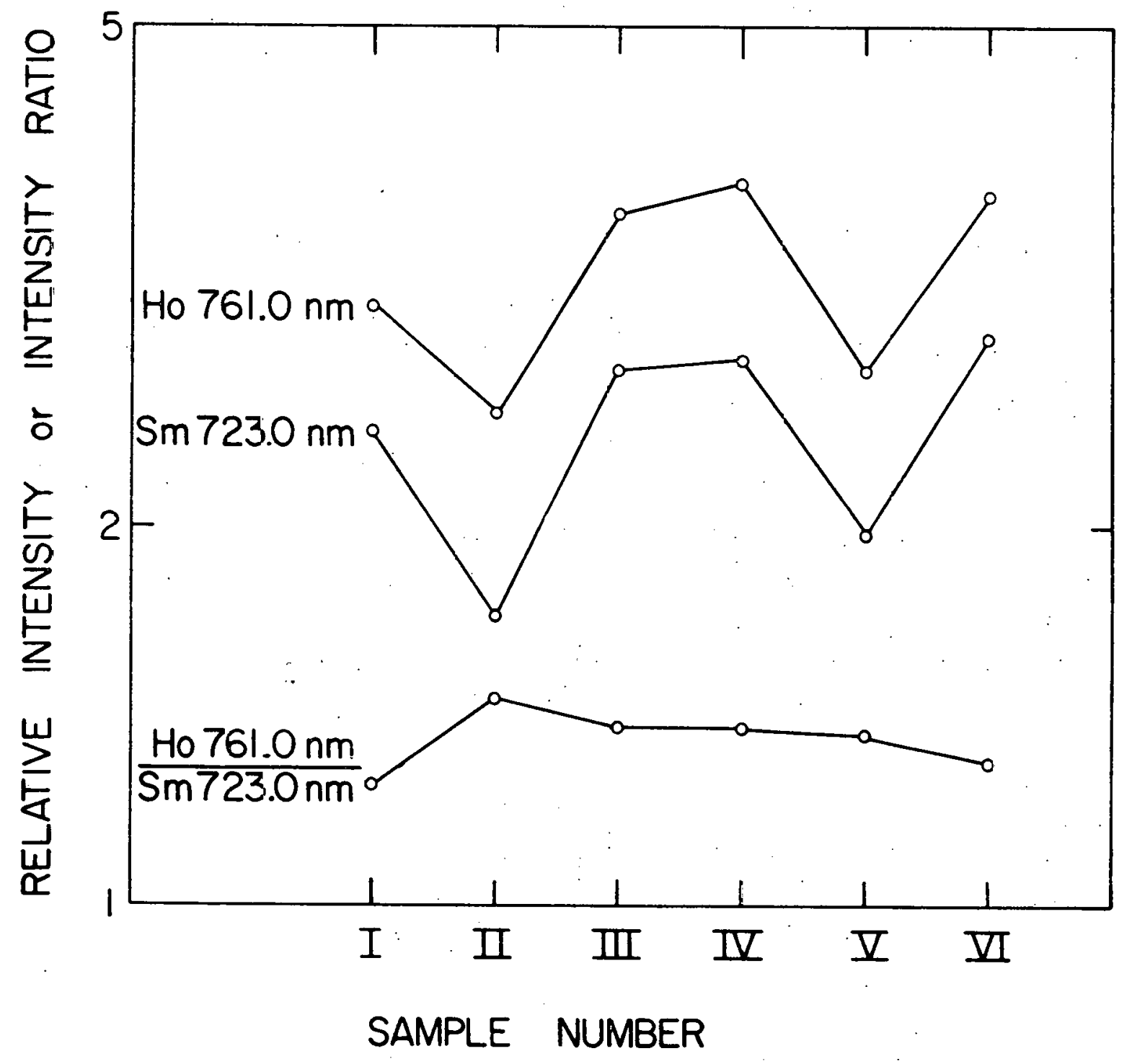




\section{THIS PAGE}

\section{WAS INTENTIONALLY \\ LEFT BLANK}


Figure 11. Effect of internal standardization in compensating for the variation of the Ex luminescen:e up on the addition of non-rare earth impurities. All samples contain $11 \mathrm{ppm}$ Er. Sample I, no additior.s; Sample II, $10 \mathrm{Cpm} \mathrm{Na}$, Sample III, $100 \mathrm{ppm} \mathrm{Ca;} \mathrm{Sample} \mathrm{IV,} 100 \mathrm{ppm} \mathrm{Fe;} \mathrm{Sample} \mathrm{V,}$ $100 \mathrm{ppm} \mathrm{Al;}$ Sample VI, $100 \mathrm{ppm}$ each $\mathrm{Na}, \mathrm{Ca}, \mathrm{Fe}$, and $\mathrm{All}$ 


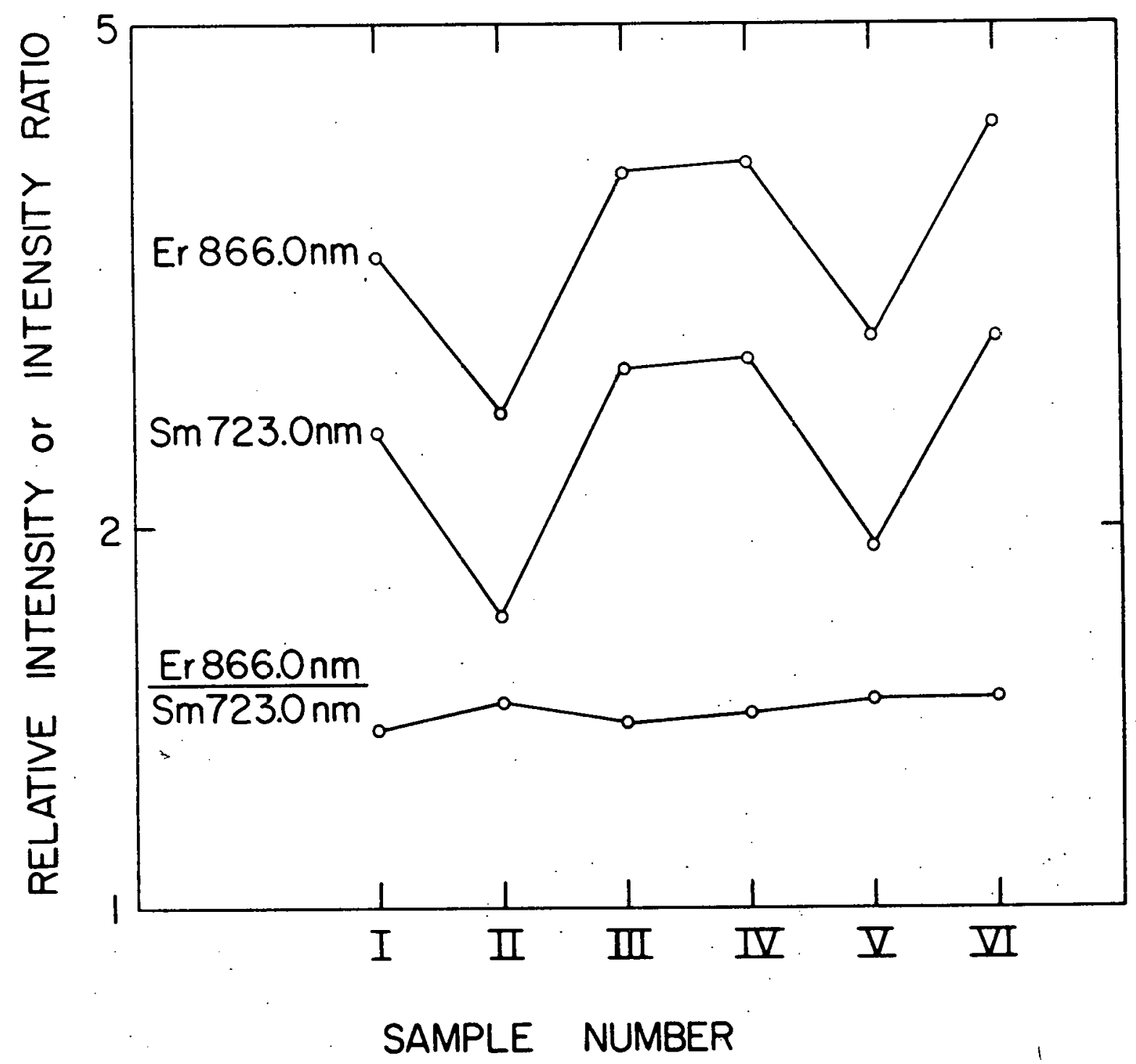


THIS PAGE

WAS INTENTIONALLY

LEFT BLANK 
Figure 12. Effect of internal stardardization in compensating for the variation of the Tm luminescence upon the addition of non-rare earth 1mpurities. All samples contain $0.7 \mathrm{ppm} \mathrm{Tm}$. Sample I, no additions; Sample II, $100 \mathrm{ppm} \mathrm{Na;} \mathrm{Sample} \mathrm{III,} 100 \mathrm{ppm} \mathrm{Ca;} \mathrm{Sample}$ IV, 100 ppm Fe; Sample V, 100 ppm Al; Sample VI, 100 ppm each Na, $\mathrm{Ca}, \mathrm{Fe}$, and $\mathrm{Al}$ 


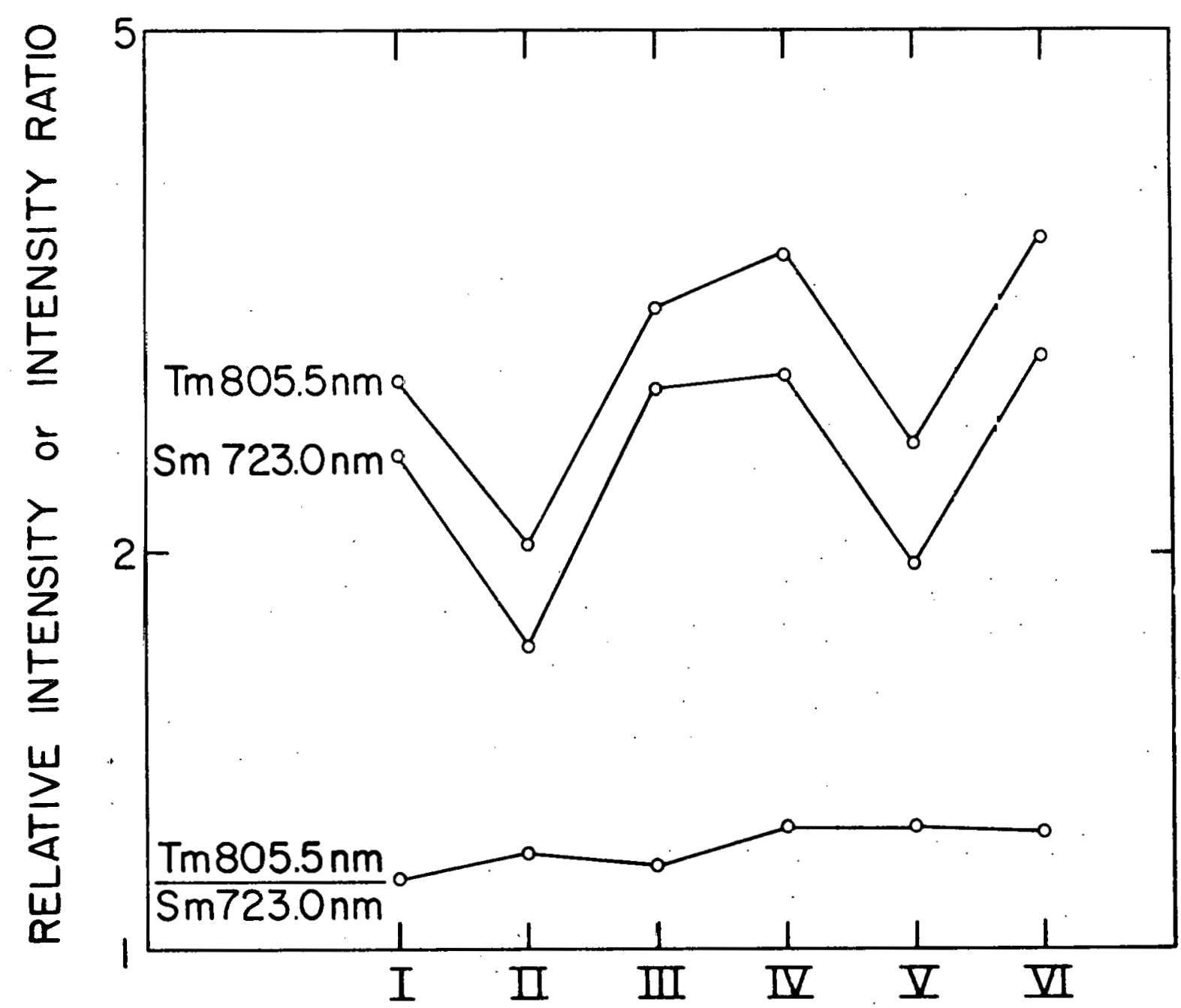

SAMPLE NUMBER 


\section{THIS PAGE}

\section{WAS INTENTIONALLY LEFT BLANK}


Figure 13. Effect of internal standardization in compensating for the variation of the $\mathrm{Yb}$ luminascence upon the addition of non-rare earth impurities. All samples contain $12 \mathrm{pPm} \mathrm{Yb}$. Sample I, no additions; Sample II, 100 ppm Na; Sample III, 100 ppm Ca; Sample IV, 100 ppm Fe; Sample V, $100 \mathrm{ppm} \mathrm{Al;}$ Sample VI, $100 \mathrm{ppm}$ each $\mathrm{Na}, \mathrm{Ca}, \mathrm{Fe}$, and $\mathrm{Al}$ 


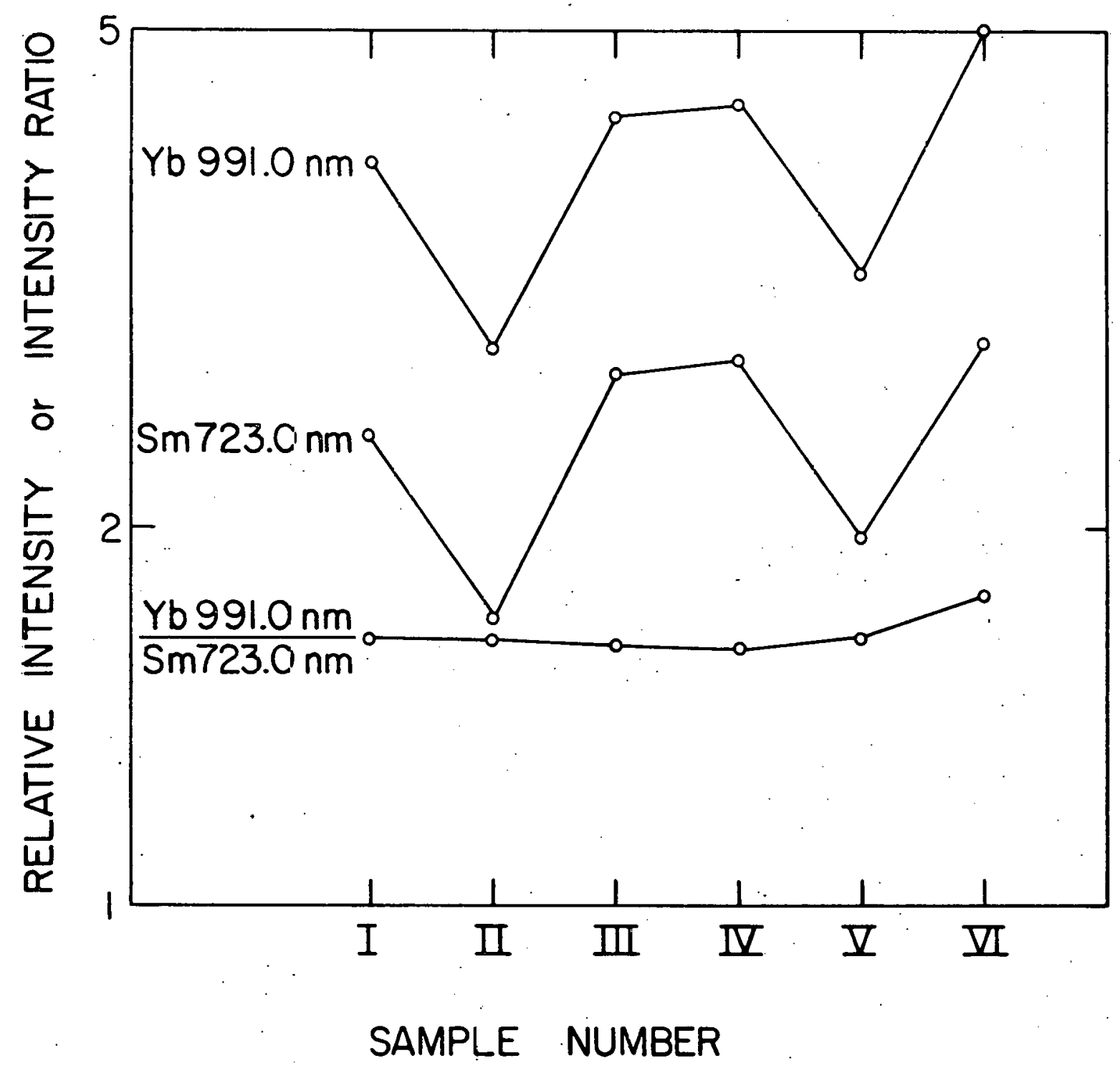


Therefore, samarium internally compensates for uncontrolled intensity fluctuations, does not interfere with the analyte 1ines, luminesces strongly, and is present at low concentrations in "pure" lutetium. Samarium is thus an acceptable choice for an internal reference element.

A typical spectrum of a sample containing approximately $6 \mathrm{ppm}$ erbium, thulium, and holmium; $18 \mathrm{ppm}$ ytterbium; and $10 \mathrm{ppm}$ samarium is shown in Figure 14. The analytical lines and the internal reference lines are marked with arrows. Generally, the measurement of the line intensities is quite easy, but some difficulty is encountered in the measurement of the holmium relative intensity at high concentrations of thulium. Thulium values greater than about $10 \mathrm{ppm}$ give a broad peak that interferes with the holmium relative intensity measurement. This high concentration value of thulium is unlikely in "pure" lutetium, but if it does occur at this level, the holmium intensity can be measured accurately if care is taken in the background correction.

The large background around the ytterbium line can also cause some difficulty. The most accurate and reproducible intensity measurements can be accomplished by using the background correction indicated by the dotted lines in Figure 14 .

\section{Phosphor Optimization}

Variations in the preparation of a phosphor can cause large differences in the 1ntensities of the luminescence of rare earths in a host. Therefore, the development of Iutetium vanadate for use in an XEOL analytical technique must involve the testing of different crystal preparation methods to attain the maximum rare earth analyte intensity and thereby, maximum sensitivity. 


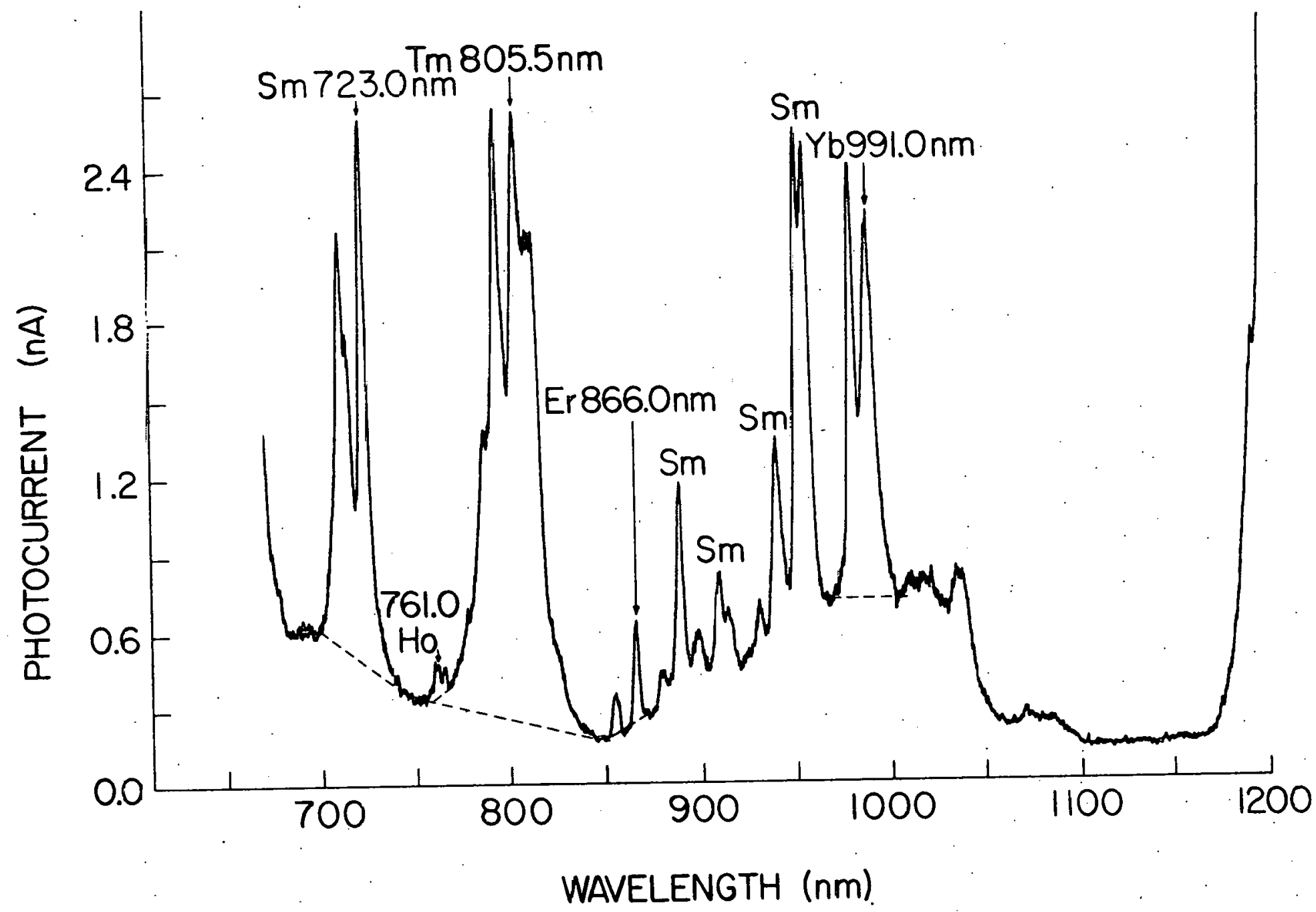
Figure 14. XEOL spectrum of $\mathrm{LuVO}_{4}$ containing $10 \mathrm{ppm} \mathrm{Sm}, 18 \mathrm{ppm} \mathrm{Yb}$, and $6 \mathrm{ppm}$
each Ho, Er, and $\mathrm{Im}$ 
As the relative amount of each constituent used to prepare the host is changed, the luminescence intensity of trace rare earths in the phosphor also changes. $16,62,73-75$ Figure 15 demonstrates the changes in the rare earth Iine intensities as a function of the percent of the stolchiometric amount of $\mathrm{NH}_{4} \mathrm{VO}_{3}$ used to prepare the Iutetium vanadate hosts. A maximum relative intensity of the holmium, erbium, thulium, and the internal reference samarfum luminescence occurred in samples prepared at $90 \%$ of the stolchiometric amount of $\mathrm{NH}_{4} \mathrm{VO}_{3}$ (1.e. 1.8 moles $\mathrm{NH}_{4} \mathrm{VO}_{3}$ and 1 mole $\mathrm{Lu}_{2} \mathrm{O}_{3}$ ). In contrast to these maxima, the ytterbium luminescence decreased with the addition of increasing amounts of $\mathrm{NH}_{4} \mathrm{vO}_{3}$. In order to maximize at. least three of the four analytes, the phosphors were prepared using $90 \%$ of the stoichiometric $\mathrm{NH}_{4} \mathrm{VO}_{3}$. An interpretation of the maxima and the anomalous ytterbium behavior based on information gathered to date would be pure speculation and w111 not be attempted.

Care must be taken, however, In the weighing of the amounts of $\mathrm{NH}_{4} \mathrm{VO}_{3}$ and $\mathrm{Lu}_{2} \mathrm{O}_{3}$ used to form the hosts because inconsistencies will affect the ytterblum luminescence differently than the samarium luminescence (Figure 15). Samarium, then, is not an effective internal reference for ytterbium for changes in the relative amount of the constituents used to prepare the phosphor.

Although the effect of ignition time on the rare earth luminescence has been shown to be an important factor in many analytical host preparations, $16,23,46,49,50,73,76-78$ Figure 16 shows that this varlable has little effect on the luminescence of the rare earths in lutetium vanadate. One hour Ignition time was used in all phosphor preparations because of the 


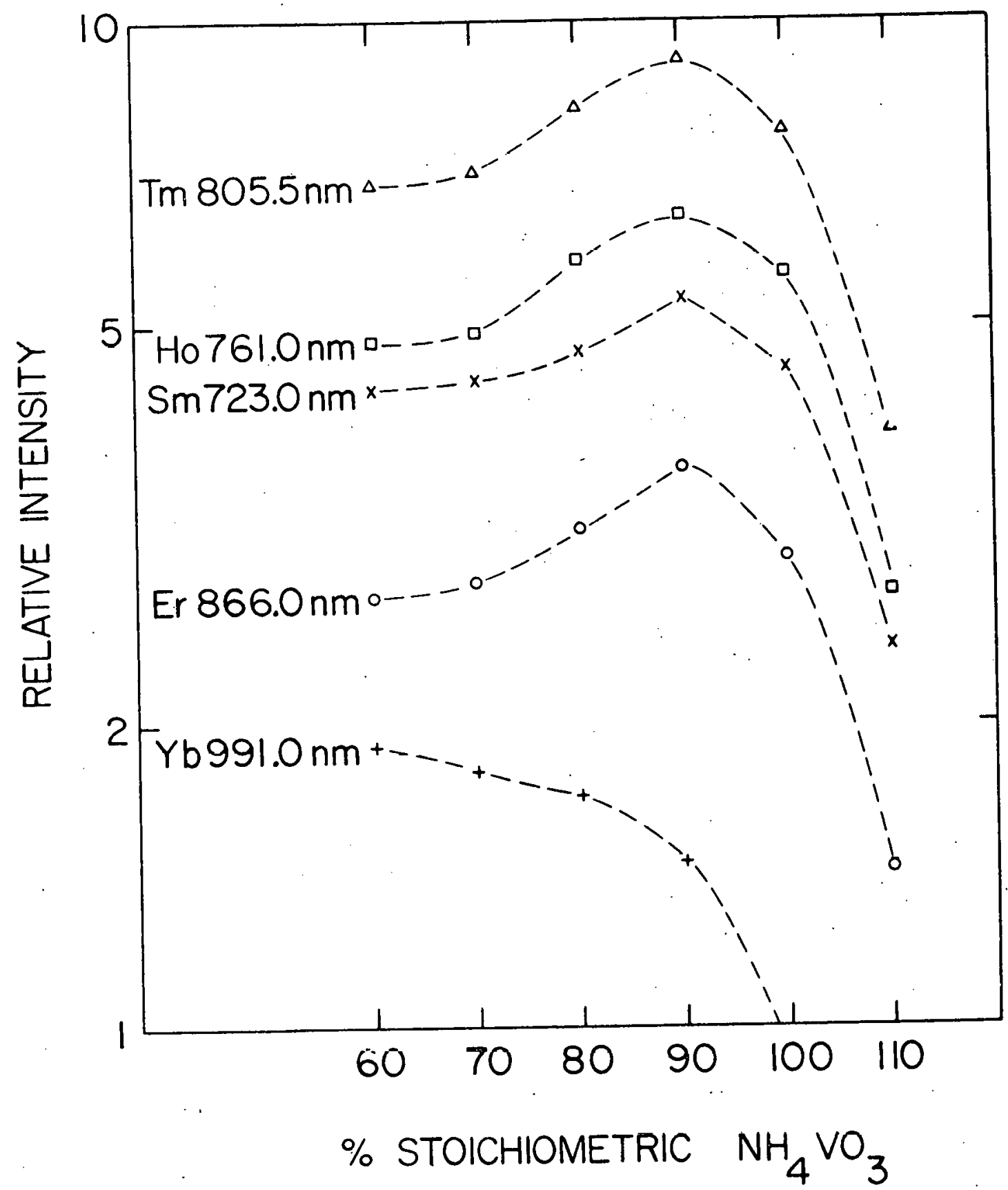

Figure 15. The relationship between the luminescence intensity of rare earth impurities and the amount of $\mathrm{NH}_{4} \mathrm{VO}_{3}$ used to prepare Luvo, A11 phosphors were ignted for one hour at $1200^{8} \mathrm{C}$ 


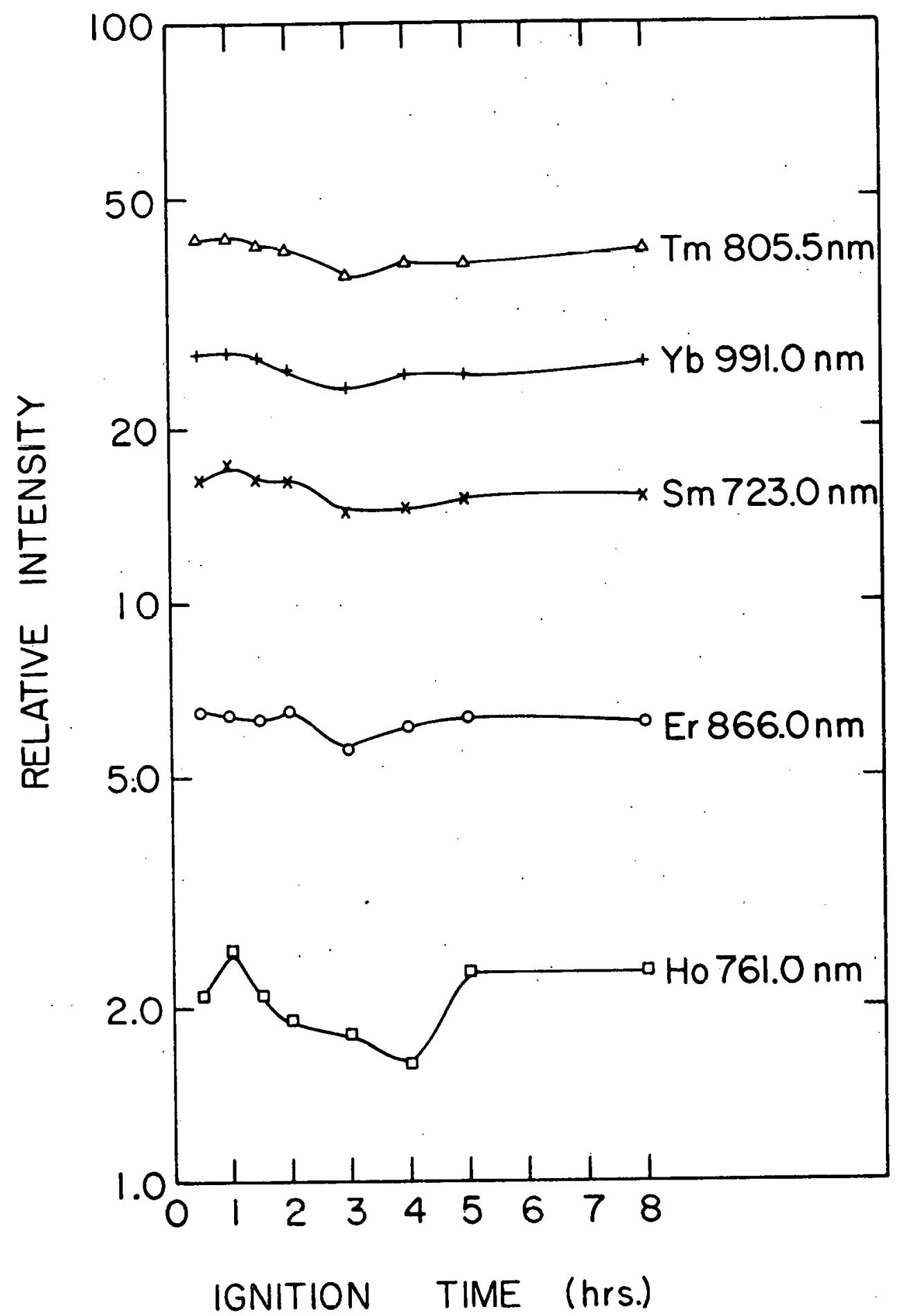

Figure 16. The relationship between the luminescence intensity of rare earth impurities and the ignition time. Alll samples were tgnited at $1200^{\circ} \mathrm{C}$ 
slightly higher relative intensity of the rare earths in a host prepared in this manner.

Ignition temperature has also been reported to be an important variable in obtaining optimal luminescence of the analytes in a phosphor. $16,23,46,49,50,61,73,76-78$ Figure 17 shows the change in the impurity luminescence as a function of temperature and indicates that phosphors prepared between $1100^{\circ} \mathrm{C}$ and $1200^{\circ} \mathrm{C}$ have stronger luminescence than hosts ignited at different temperatures. The phosphors were therefore prepared at an ignition temperature of $1200^{\circ} \mathrm{C}$ to take advantage of this stronger luminescence.

The ignition time and temperature affects the intensity of each of the rare earths, including samarium, similarly as shown in Figures 16 and 17 . Therefore, inconsistencies in these two preparation factors will have little effect on the analytical determinations because the samarium will compensate for the changes in intensity.

In the preparation of the phosphate host, a compound $\left(\mathrm{Na}_{4} \mathrm{P}_{2} \mathrm{O}_{7} \cdot 1 \mathrm{OH}_{2} \mathrm{O}\right)$ was added to improve the crystallinity of the host and presumably increase the impurity Iuminescence. ${ }^{24,70}$ Similarly Tsuyoshi Kano and 0tomo ${ }^{79}$ have suggested the use of small amounts of $\mathrm{Na}_{2} \mathrm{~V}_{2} \mathrm{O}_{7}$ in the preparation of vanadates. Several lutetium vanadate hosts were prepared using small amounts of $\mathrm{Na}_{2} \mathrm{~V}_{2}{ }^{0}{ }_{7}$, but the luminescence of the rare earths was slightly quenched under X-ray excitation and the procedure was not adopted.

The addition of a compound such as $\mathrm{NaNO}_{3}{ }^{16}$ or $\mathrm{Na}_{2} \mathrm{SO}_{4} 77$ is common in phosphor production as a flux to provide "a fluid phase for solution and transport of ingredients and increased surface reactivity and atomic 


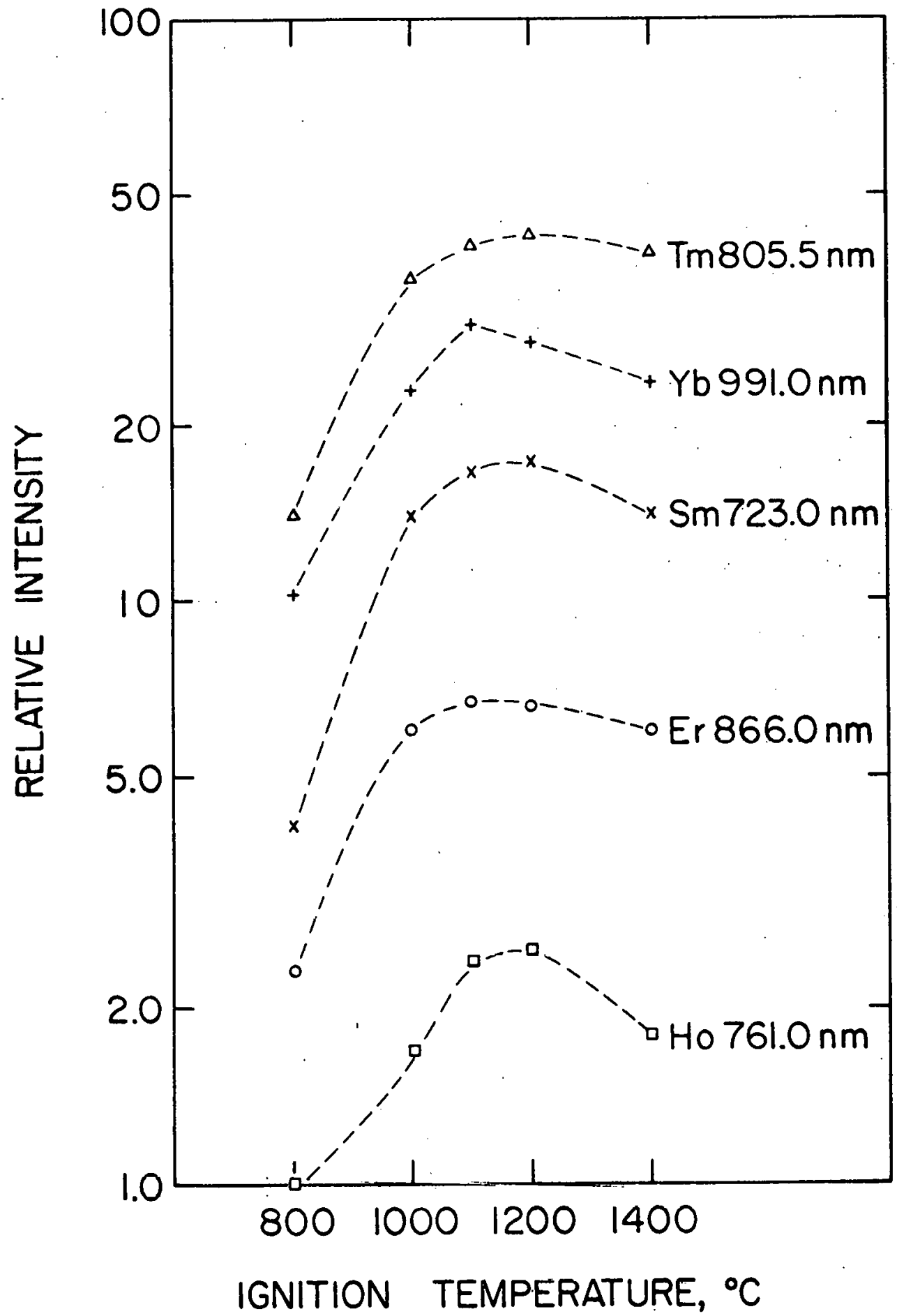

Figure 17. The relationship between the luminescence intenstty of rare earth impurities and the Ignition temperature. All samples were Ignited for one hour 
mobllity to facilitate growth." 74 However, a flux is beneficial only in phosphors which are to be excited by low energy photons (e.g. UV), and not those excited by high energy photons (e.g. X-ray) because the flux causes quenching of the optical luminescence initiated by high energy photons. $^{74}$ In addition, for a reason which is not understood, a flux improves a phosphor prepared at low temperatures $\left(500-600^{\circ} \mathrm{C}\right)$, but not at the higher temperatures $\left(1000^{\circ} \mathrm{C}\right) .51$

The amount of lutetium vanadate phosphor prepared is of little consequence because the $X$-rays are calculated to be $99 \%$ absorbed at a $0.5 \mathrm{~mm}$ depth in the rare earth phosphor; ${ }^{9}$ therefore, the phosphor could be prepared from as little as $0.01 \mathrm{~g}$ of the rare earth oxide. 9

\section{Sample Preparation}

The knowledge obtained in the phosphor optimization studies discussed above was factored into the sample preparation procedures, so as to develop maximal analyte luminescence. Lutetium oxide samples were dissolved in hot dilute nitric acid and the equivalent of $10 \mathrm{ppm}$ samarium internal reference was added from a stock samarium solution. This mixture was evaporated to dryness on a hot plate, heated at $600^{\circ} \mathrm{C}$, ground in agate mortar, and ignited at $1200^{\circ} \mathrm{C}$ for one hour.

The vanadate was formed by adding $90 \%$ of the stoichiometric amount of ammonium metavanadate to a portion of lutetium oxide $\left(0.13 \mathrm{~g} \mathrm{NH}_{4} \mathrm{VO}_{3}\right.$ and $0.25 \mathrm{~g} \mathrm{Lu}_{2} \mathrm{O}_{3}$ ), mixing in an agate mortar, and heating for five minutes at $600^{\circ} \mathrm{C}$. The sample was reground and ignited at $1200^{\circ} \mathrm{C}$ for one hour. The light yellow powder thus produced was pressed in an aluminium planchet ( $1 \mathrm{~cm}$. in diameter) which $\mathrm{f} 1 \mathrm{ts}$ in the $\mathrm{X}$-ray sample holder. Only twenty 
minutes was necessary for the recording of the XEOL spectrum from $1,000.0 \mathrm{~nm}$ to $600.0 \mathrm{~nm}$, measurement of the peaks, and conversion of the intensity ratio to concentration.

The entire analytical process required an elapsed time of only four hours. This time is much shorter than the two days necessary for mass spectroscopic analyses. 


\section{RESULTS}

\section{Detection Limits}

The applicability of an analytical method for the determination of rare earth impurities can be demonstrated by the detection limits. The detection limit is defined as that concentration of an element necessary to produce a signal equal to three times the standard deviation of the background noise and is computed using the following formula:

$$
\underset{(\mathrm{ppm})}{\operatorname{Detection~Limit}}=\frac{3 \cdot \mathrm{A} \cdot \sigma_{B}}{\overline{\mathrm{RI}}}
$$

where $A=$ concentration of the analyte in $\mathrm{ppm}$

$$
\begin{aligned}
\sigma_{B}= & \text { standard deviation of the background noise } \\
\overline{R I}= & \text { average relative intensity of the luminescence of a sample } \\
& \text { containing } A .80
\end{aligned}
$$

In most analytical methods, $\sigma_{B}$ is usually calculated from background noise in a sample containing no analyte, ${ }^{80}$ however in lutetium oxide analysis by XEOL, even the "blank" sample contains measurable amounts of the analytes. Therefore, $\sigma_{B}$ must be calculated from the average value of the background noise on elther side of the analytical line being studied. 80

The relative intensity of the rare earth luminescence and background nolse of eleven identically prepared samples of lutetium vanadate phosphors were used to calculate the detection limits on Table 3 . In addition to the XEOL detection 1imfts, the detection limits of other analytical methods commonly used for rare earth determinations are also presented. A meaningful comparison of these detection limits is difficult due to the lack of 
Table 3. Estimated detection limfts ( $\mu$ g analyte/gLu ${ }_{2} \mathrm{O}_{3}$ )

\begin{tabular}{|c|c|c|c|c|c|c|c|}
\hline Element & XEOL & Photographic $\frac{\text { SSMS }}{\text { Pic }}$ & $\begin{array}{l}12 \\
\text { Electrical }\end{array}$ & UVEOL $^{16}$ & $\begin{array}{l}\text { Flame } \\
\text { Emission }\end{array}$ & Flame $^{5}$ & ${ }_{\text {Emisston }}{ }^{6}$ \\
\hline Ho & 2 & 0.1 & 0.02 & 5 & 40 & 100 & 400 \\
\hline Er & 0.4 & 0.3 & 0.05 & 0.2 & 20 & $300^{\circ}$ & 10 \\
\hline & . & & & & & & \\
\hline Tm & 0.05 & 0.1 & 0.02 & 1.4 & 20 & 100 & .10 \\
\hline $\mathrm{Yb}$ & $i$ & 0.5 & 0.01 & 10 & 2 & 40. & 2 \\
\hline
\end{tabular}


Information concerning the calculation of the limits in the other methods, however, a cursory review Indicates that only the SSMS and the UVEOL methods have detection linits comparable to XEOL.

\section{Analytical Calibration Curves}

The conversion of the intensity ratio to the concentration of the analyte is accomplished by an analytical caltbration curve. The initial plotting of the calibration curves in this study resulted in a straight Ine with a positive $y$-intercept indicating the presence of a residual amount of the element in the base lutetium oxide as shown in the ytterbium curve in Figure 18. The residual amount of ytterbium was calculated by extrapolating the curve to zero intensity ratio and measuring the negative value of the residual on the concentration axis.

The original pure lutetium oxide used as a base for the calibrating reference samples was found to contain $12 \mathrm{ppm}$ residual ytterbium and therefore, the use of the ytterbium callbration curve below this rather high concentration is subject to significant error. An additional set of three standards was prepared from a lutetium oxide host containing one ppm ytterbium to extend the calibration curve down to a lower concentration level (Figure 19).

The working calibration curves shown in Figures 19,20,21, and 22 were constructed by plotting $\log$-intensity ratio versus 1 og-total analyte (residual plus added analyte). The vertical bars on each curve correspond to the range of intensity ratios of three samples prepared at each concentration value and the circles represent the average of these three values. 


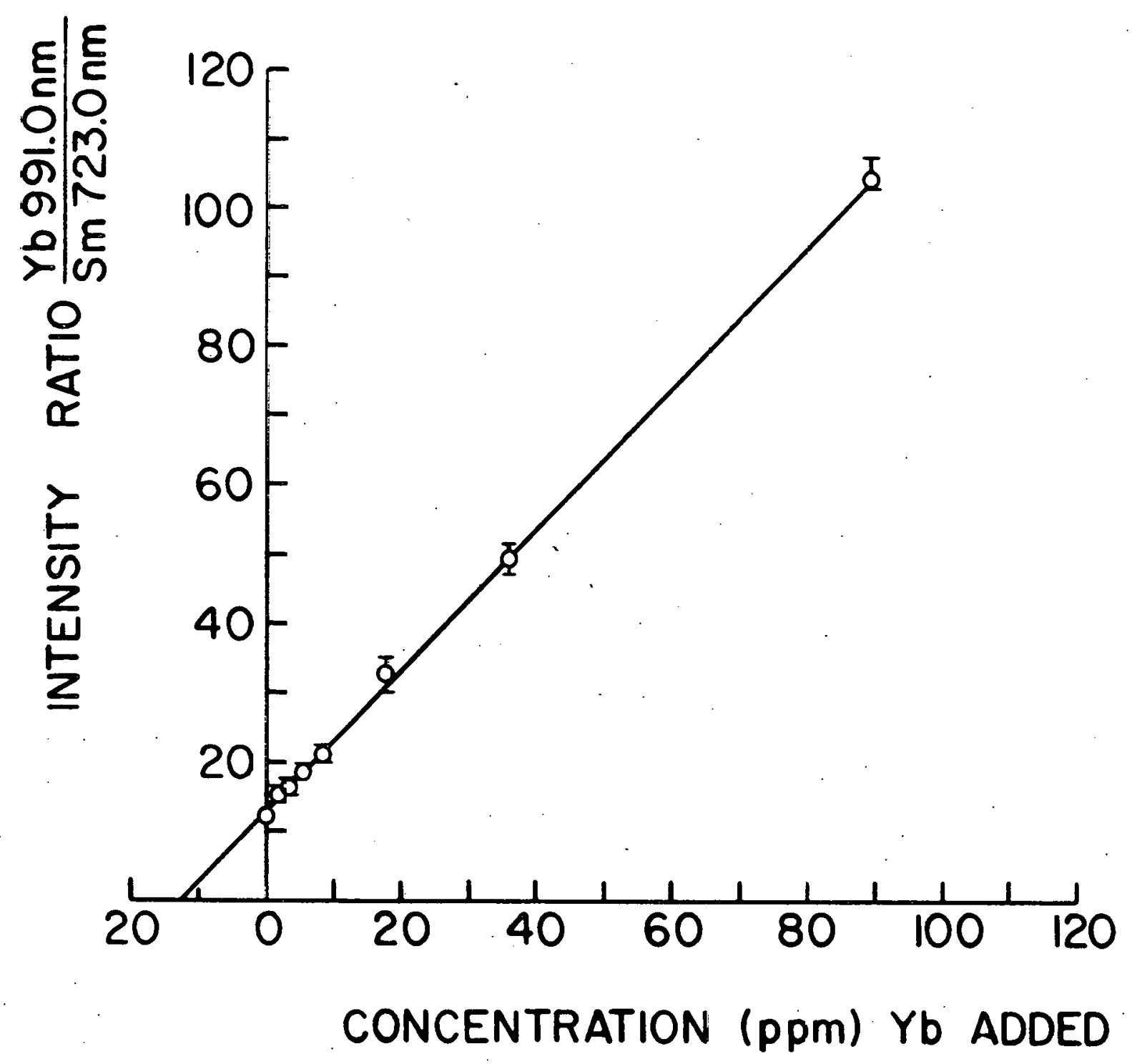

Figure 18. The determination of residual $\mathrm{Yb}$ in $\mathrm{Lu}_{2} \mathrm{O}_{3}$ base material by the standard additions method 


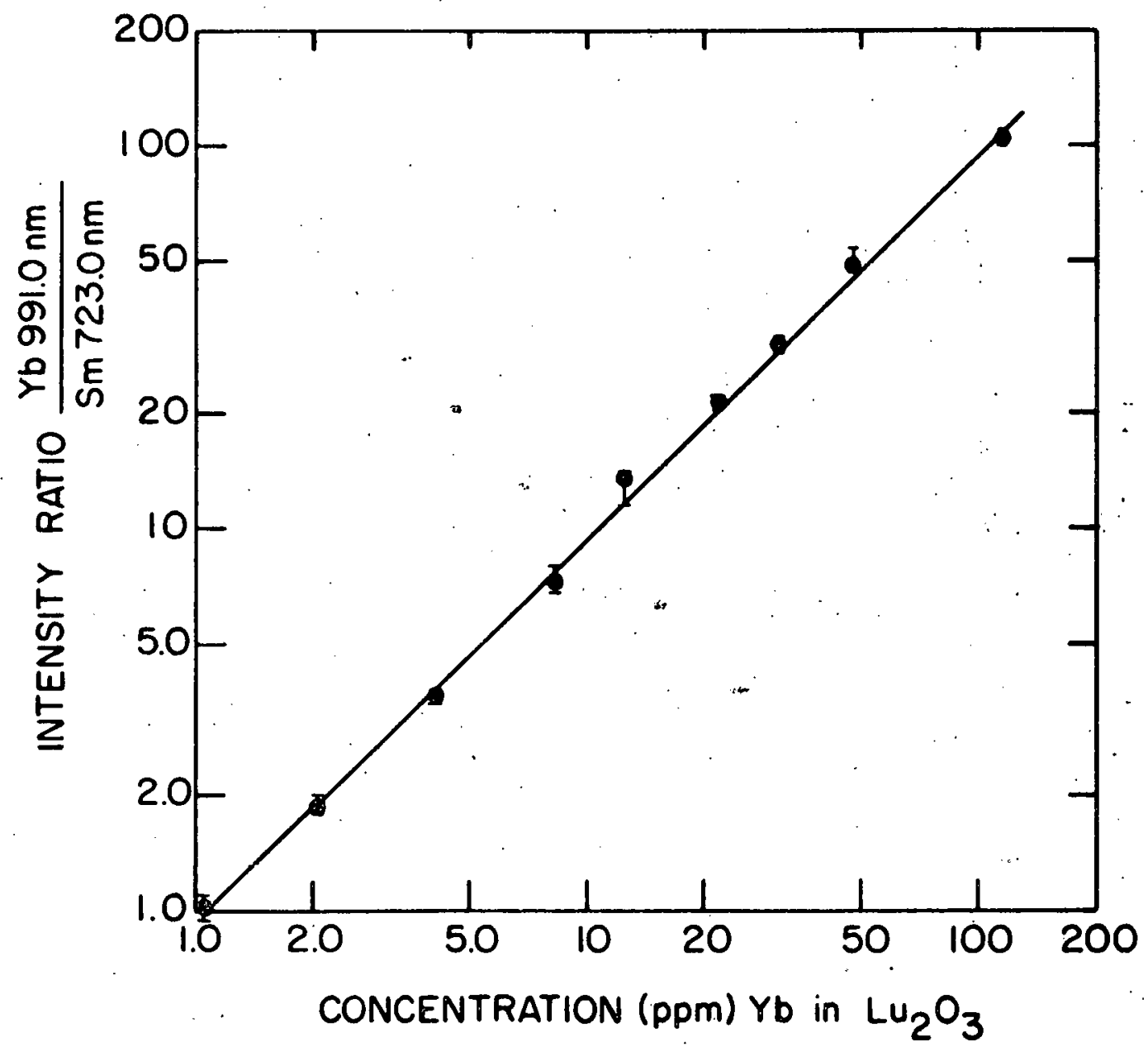

Figure 19. Analytical curve for the determination of ytterbium 


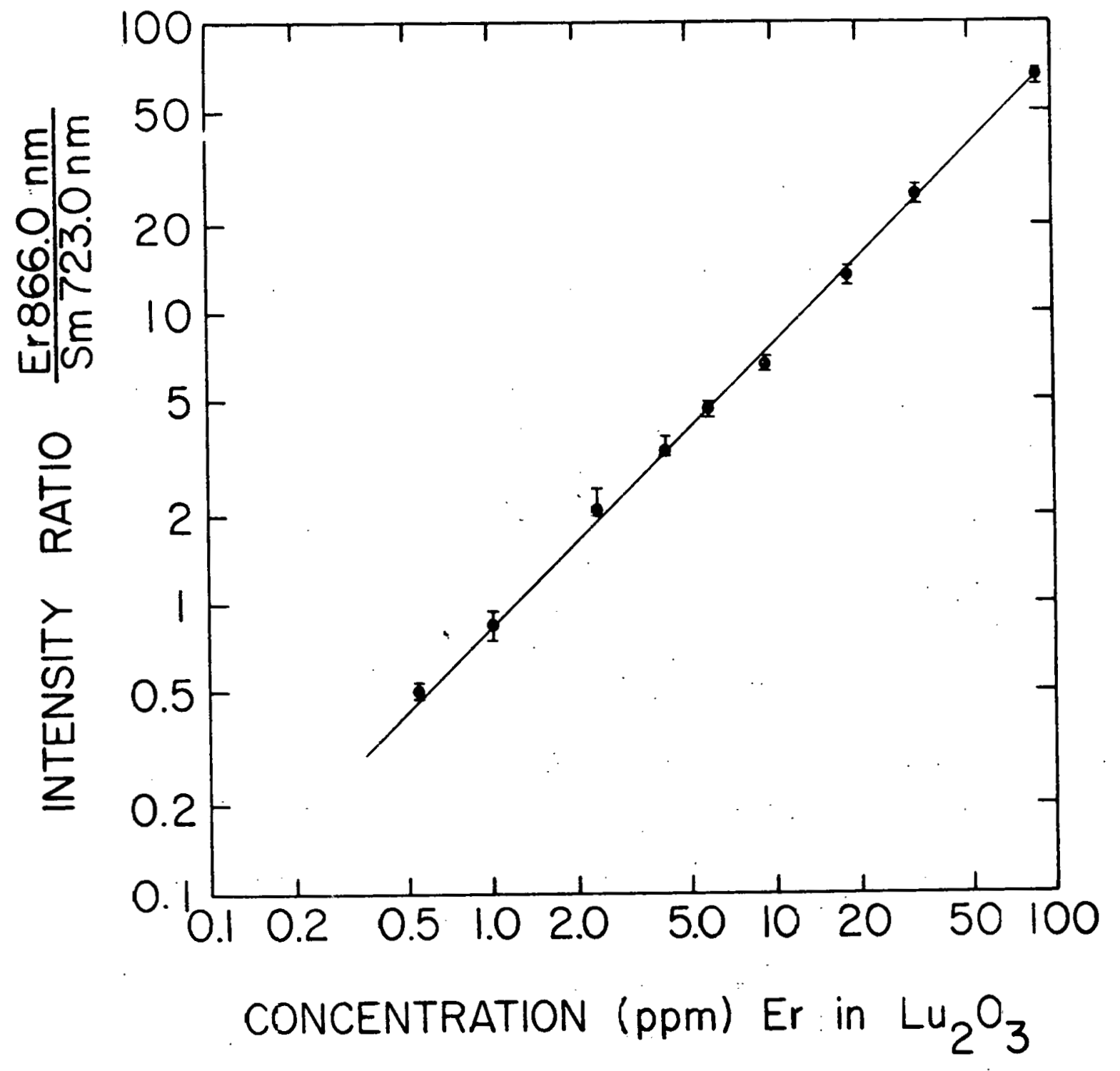

Figure 20. Analytical curve for the determination of erbium 


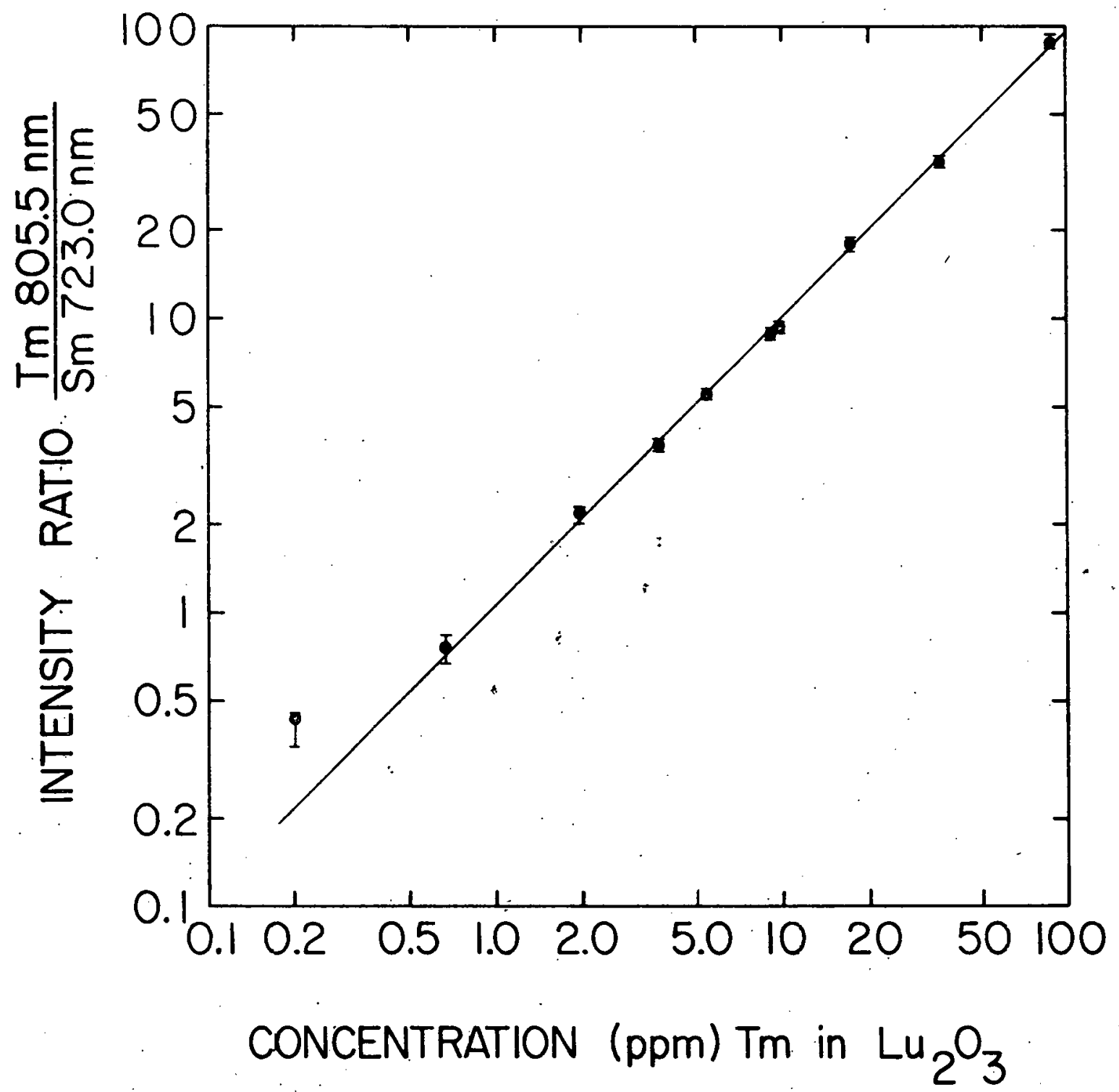

Figure 21. Analytical curve for the determination of thulium 


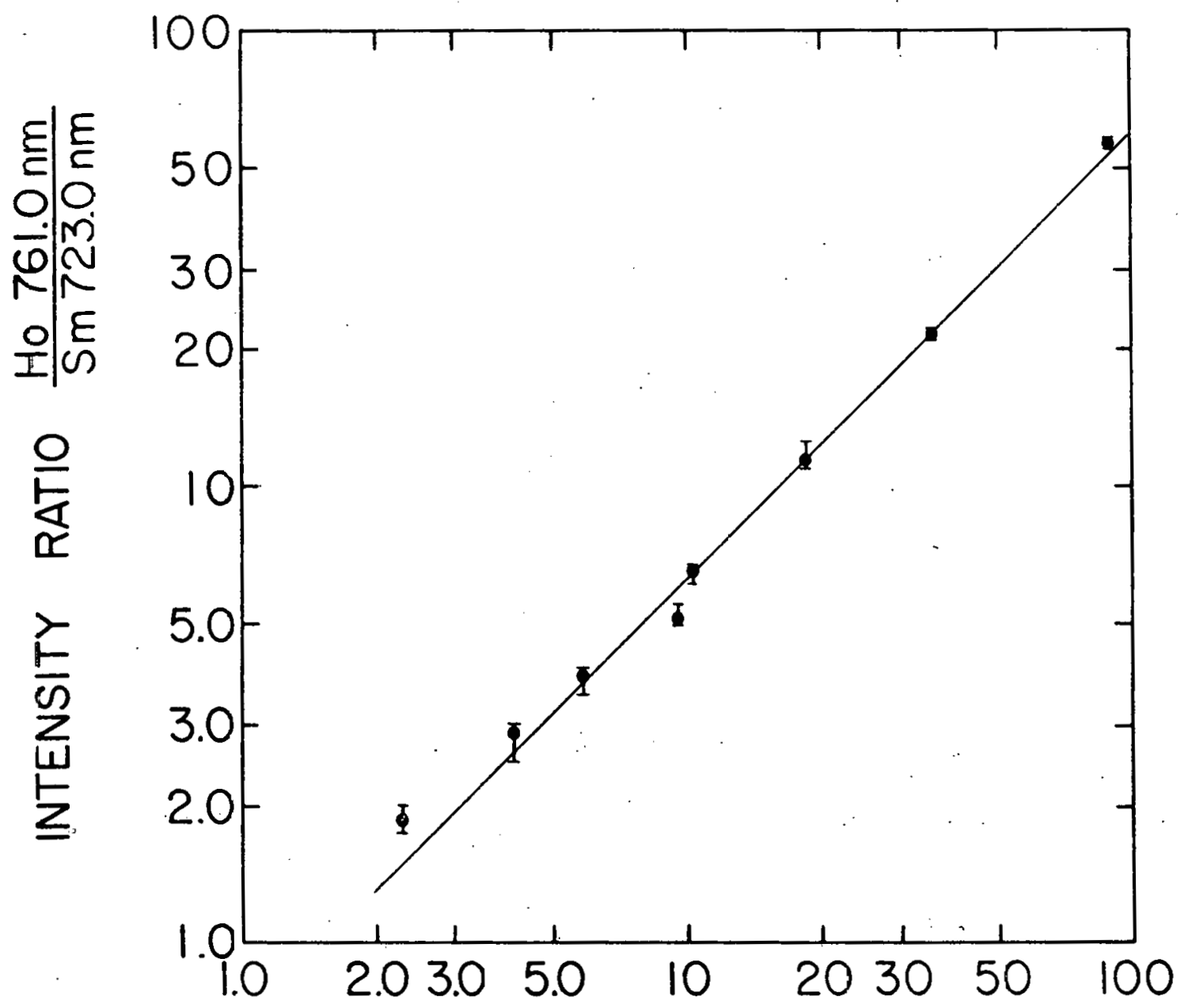

CONCENTRATION (ppm) $\mathrm{HO}$ in $\mathrm{Lu}_{2} \mathrm{O}_{3}$

Figure 22. Analytical curve for the determination of holmium 
The caltbration curves are quite linear with only two major deviations present at $0.2 \mathrm{ppm}$ thulium and $2.1 \mathrm{ppm}$ holmium. The error in the thulium curve (Figure 21) is probably due to a slight miscalculation in the residual correction. The error in the lowest holmfum value (Figure 22) Is due to the closeness of this concentration value to the detection 1 imit of holmium $(2.0 \mathrm{ppm})$.

The internal reference element must be able to compensate not only for the enhancement or depression of the analytical lines at one analyte concentration as shown previously, but also must be able to compensate over the entire range of analysis ( $1 . e$. , from fractional ppm to $100 \mathrm{ppm}^{34}$ ) and give accurate analytical results. Six samples of lutetium vanadate were prepared containing different concentrations of the rare earth analytes and $10 \mathrm{ppm}$ samarium to check the utility of the Internal reference over the entire concentration range. Amounts of one or more of the most common non-rare earth impurities (i.e., nickel, aluminum, iron, calcium, and magnesium ${ }^{34}$ ) in excess of the concentrations likely to be encountered in purified lutetium oxide were added to each rare earth doped sample. The XEUL analytical results of these prepared lutetium vanadates is compared with the total known rare earths present in the sample on Table 4. The errors encountered in the analysis are within the limits of precision for the XEOL analytical method (see the next section, "Precision") and therefore, analysis of completely different samples containing dissimflar impurities should be accurate over the entire concentration range investigated. 
Table 4. Effects of non-rare earth Impurities (a11 values reported. In ppm)

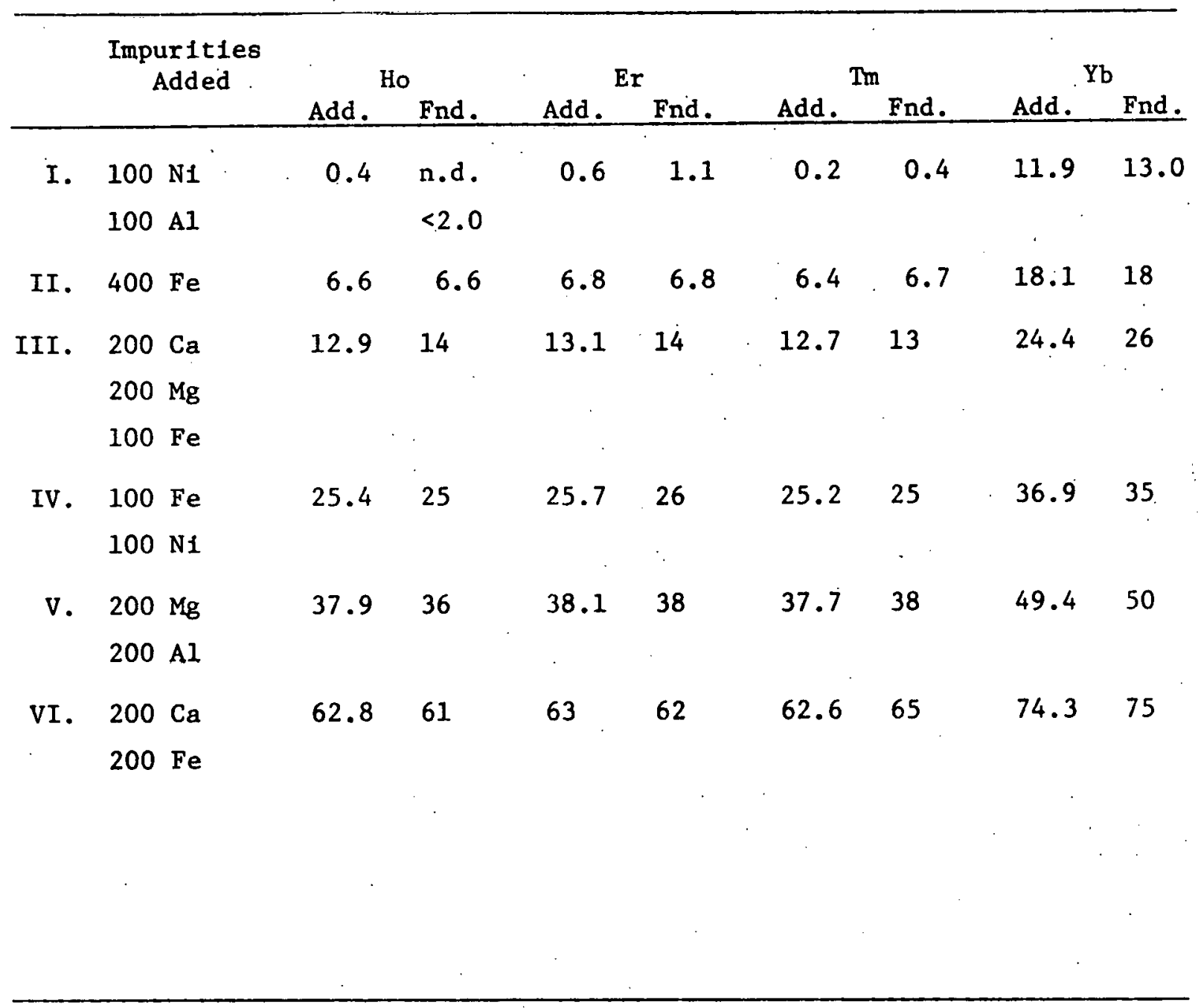




\section{Prectsion}

The precision of an analytical method may be determined from the reproducibility of the results obtained from several identical samples. The precision is often expressed by the coefficient of variation calculated using the following formula:

$$
\text { Coefficient of Variation }=\frac{\sigma_{\text {Ir }}}{\frac{\sigma}{I R}} \times 100 \%
$$

where $\sigma_{1 r}=$ standard deviation of the intensity ratio

$$
\overline{I R}=\text { average value of the intensity ratio. }
$$

The coefficient of variation of this XEOF method was determined using the Intensity ratios of ten lutetium vanadate samples prepared in an identical manner from a stock lutetfum oxide base material doped with each analyte. The results of this study (Table 5) indicate an average coefficient of variation of $5 \%$ at concentrations ten times the analyte detection limit and $12 \%$ at concentrations about twice the detection limit. These values compare favorably with the precision of mass spectrometry; for which the coefficient of variation is 25 to $30 \%^{10,13}$ for concentrations of rare earths from 10 to $100 \mathrm{ppm}$ and $50 \%^{10}$ at values less than $10 \mathrm{ppm}$. The coefficient of variation of a typical UV excited method for rare earth determinations 1s $20 \%$ at concentrations of about 10 to $50 \mathrm{ppm} .63$

\section{Accuracy}

The measurement of the relative accuracy of the XEOL method for determining holmium, erbium, thulium, and ytterblum in actual lutetium samples is difficult because of the poor precision of alternate techniques 
Table 5. Prectsion study

\begin{tabular}{lcc}
\hline Element & Concentration (ppm) & Coefficient of Variation (\%) \\
\hline Ho & 5 & 10 \\
& 33 & 4 \\
Er & 1 & 18 \\
& 10 & 6 \\
Tm & 0.2 & 9 \\
& 2 & 5 \\
Yb & 12 & 9 \\
& 22 & 4 \\
\hline
\end{tabular}


of analysis. However, a comparison of the analysis by XEOL, SSMS, and DC arc emission spectrography on five unknowns obtained from the Ames Laboratory Metals Development groups Indicates (Table 6) agreement within the limits of precision. Note that in all samples except $A$, the holmium content is at a level below the detection limits of each method. 
Table 6. Comparison of analytical data

\begin{tabular}{|c|c|c|c|c|c|c|c|c|c|}
\hline \multirow[t]{3}{*}{ Sample } & \multicolumn{9}{|c|}{ Rare Earth Concentration (ppm) } \\
\hline & \multicolumn{2}{|c|}{ Ho } & \multicolumn{2}{|c|}{ Er } & \multicolumn{2}{|c|}{$\operatorname{Tm}$} & \multicolumn{2}{|c|}{$\mathrm{Yb}$} & \multirow[b]{2}{*}{ EMS } \\
\hline & $\mathrm{XEOF}$ & $\overline{S S M S}$ & $\mathrm{XEO} \overline{\mathrm{F}}$ & SSMS & $\mathrm{XEOF}$ & SSMS & $\mathrm{XEOF}$ & SSMS & \\
\hline A & 4.2 & 4.1 & 0.7 & 1.7 & 0.3 & 0.3 & 1.0 & 0.9 & - \\
\hline B & $<2$ & $<0.1$ & 1.0 & 0.4 & 0.3 & 0.2 & 1.2 & 1.4 & - \\
\hline C & $<2$ & $<0.1$ & 0.6 & 0.4 & 0.3 & 0.1 & 3.0 & 3.2 & - \\
\hline D & $<2$ & $<0.1$ & 0.7 & 0.8 & 0.3 & 0.2 & 10 & 10 & 13 \\
\hline E & $<2$ & $<0.1$ & 0.7 & 0.7 & 0.3 & 0.2 & 9.3 & 6.8 & 10 \\
\hline
\end{tabular}




\section{SUMMARY}

The X-ray excited optical luminescent determination of holmium, erbrium, thulium, and ytterbium at concentrations of a fractional ppm to $100 \mathrm{ppm}$ in lutetium has been studied and discussed. An analytically effective lutetium vanadate host for the luminescence of the rare earths was identifled and optimized. The use of the internal reference element samarium was found to make the analyses much more precise than the methods now available for the determinations of trace rare earths in lutetium (i.e. mass spectroscopy and UV excited luminescence). The XEOL method was shown to be as sensitive as the mass spectroscopic analysis for a much lower cost and shorter determination time. Linear calibration curves were obtained from prepared samples and even the addition of up to $500 \mathrm{ppm}$ of iron, aluminum, calcium, magnesium and/or nickel did not affect the linearity. 


\section{BIBLIOGRAPHY}

1. J. E. Powe11 in "The Rare Earths," F. H. Spedding and A. H. Daane, Eds., J. Wiley and Sons, New York, N.Y., 1961, pp 55-73.

2. T. Moeller and J. C. Brantley, Anal. Chem., 22, 433 (1950).

3. R. N. Kniseley, V. A. Fassel, R. W. Tabeling, B. G. Hurd, and B. B. Quinney, Spectrochim. Acta, 13, 300 (1959).

4. R. N. Kniseley, V. A. Fassel, B. B. Quinney, G. Tremme1, W. A. Gordon, and W. J. Hayles, Spectrochim. Acta, 12, 332 (1958).

5. R. N. Kniseley, C. C. Butler, and V. A. Fassel, Anal. Chem., 41, 1494 (1969).

6. E. L. DeKalb, Iowa State UnIversity, unpubiished data, 1973.

7. F. W. Lytle and H. H. Healy, Anal. Chem., 31, 809 (1959).

8. C. Plowman, Analyst, 96, 776 (1971).

9. R. J. Jaworowski, J. F. Cosgrove, D. J. Bracco, and R. M. Walters, Spectrochim. Acta, 23B, 751 (1968).

10. J. F. Cosgrove, D. W. Oblas, R. M. Walters, and D. J. Bracco, Electrochem. Techno1., 6, 137 (1968).

11. R. Clark, Iowa State University, personal communication, 1974 .

12. R. J. Conzemius, Iowa State University, personal communication, 1974 .

13. D. A. Griffith, R. J. Conzemius, and H. J. Svec, Talanta, 18, 665 (1971).

14. A. V. Antonov, L. V. Kulevski1, and Sh. G. Melamed, Zavod. Lab., 37, 518 (1971).

15. L. I. Ankina and A. V. Karyakin, Russ. Chem. Rev., 33, 571 (1964).

16. N. S. Poluéktov, N. I. Smirdova, N. P. Efryushina, S. A. Gaba, and S. M. Gorshkova, Zavod. Lab., 37, 266 (1971).

17. K. A. Wickersheim, R. A. Buchanan, and L. E. Sobon, Ana1. Chem., 40, 807 (1968).

18. S. Larach, Ana 1. Ch1m. Acta, 4l, 189 (1968). 
19. R. N. Kniseley, F. C. Laabs, and V. A. Fassel, Ana1. Chem., 41, 50 (1969).

20. J. Makovsky, W. Low, and S. Yatsiv, Phys. Lett., 2, 186 (1962).

21. V. E. Derr and J. J. Gallagher in "Quantum Electronics,". Paris 1963 Conference, Vol. I, P. Grivet and N. Bloembergen, Eds., Columbia Univ. Press, New York, N.Y., 1964, pp 817-824.

22. R. C. Linares, J. B. Schroeder, and L. A. Hurlbut, Spectroch1m. Acta, 21, 191.5 (1968).

23. W. E. Burke and D. L. Wood in "Advances in X-Ray Analysis," Vol. XI, J. B. Newkirk, G. R. Mallett, and H. G. Pfeiffer, Eds., Plenum Press, New York, N.Y., 1968, pp 204-213.

24. A. P. D'S11va and V. A. Fasse1, Ana1. Chem., 45, 542 (1973).

25. Matsuji Sato, Hiroshi Matsui, and Tadao Matsubura, Jap. Anal., 20, 70 (1971).

26. Naohisa Sasak1, Jap. Ana1., 17, 1387 (1968).

27. W. A. Shand, J. Mater. Sc1.; 3, 344 (1968).

28. Takunosuke Nakajima, Yoshihiko Ouch1, Hirochi Kawaguchi, and Kyoichiro Takashama, Jap. Ana1., 19, 1183 (1970).

29. Hiroshi Kawaguchi, Tokunosuke Nakajima, Kyolchiro Takashima, and Yoshihiko Ouchi, Bunko Kenkyu, 18, 299 (1969).

30. A. P, D'Silva and V. A. Fassel, submitted for publication in Anal. Chem.

31. A. P. D'Silva and V. A. Fasse1, Ana1. Chem., 43, 1406 (1971).

32. Tokunosuke Nakajima, Hirosh1 Kawaquchi, Kyochiro Takashima, and Yoshihiko Ouchi, Bunko Kenkyu, 18, 210 (1969).

33. A. P. D'Silva, E. L. DeKalb, and V. A. Fasse1, Anal. Chem., 42, 1846 (1970).

34. I'. R. Saranathan, V. A. Fasse1, and E. I. DeKalb, Anal. Chem., 42, 325 (1970).

35. Kyoichiro Takashima, Tokunosake Nakajima, Hiroshi Kawaguchi, and Yoshihiko Ouchi, Bunko Kenkyu, 18, 262 (1969). 
36. E. L. DeKalb, A. P. D'Silva, and V. A. Fassel, Anal. Chem., 42, 1246 (1970).

37. V. A. Fasse1, E. L. DeKalb, and A. P. D'Silva in "Analysis and Applications of Rare Earth Materials," 0. B. Michelsen, Ed., Universitetsforlaget, 0s10, Norway, 1973, pp 109-122.

38. W. Low, J. Makovsky, and S. Yatsiv in "Quantum Electronics," Paris 1963 Conference, Vol I, P. Grivet and N. Bloembergen, Eds., Columbia Univ. Press, New York, N:Y., 1964, pp 655-675.

39. H. N. Hersh and H. Forest, J. Luminescence, 1, 2, 862 (1970).

40. E. R. I1mas and T. I. Savikhina, J. Luminescence, $1,2,702$ (1970).

41. I. A. Parfianovich, E. I. Sharaleva, and P. S. Ivakhnenko, Bu11. Acad. Sci. USSR, Phys. Ser., 31, 838 (1967).

42. G. Blasse and A. Bril, J. Electrochem. Soc., 115, 1067 (1968).

43. L. G. Van U1tert, J. Electrochem. Soc., 114, 1048 (1967).

44. P. R. Thornton, "Scanning Electron Microscopy," Chapman and Ha11, London, 1968, Chapter 10.

45. L. G. Van Uitert in "Luminescence of Inorganic Solfds," P. Goldberg, Ed., Academic Press, New York, N.Y., 1966, Chapter 9.

46. H. V. Leverenz, "An Introduction to Luminescence In Solids," Wiley, New York, N.Y., 1968, pp 34-58, 316-318.

47. H. V. Leverenz in "Preparation and Characterization of Solid Luminescent Materials," Symposium at Cornell University, 1946, G. R. Fonda and F. Seltz, Eds., Wiley, New York, N.Y., 1948, pp 148-163.

48. F. C. Palilla, Electrochem. Techno1., 6, 39 (1968).

49. E. L. DeKalb, V. A. Fassel, T. Taniguich1, and T. R. Saranathan, Anal. Chem., 40, 2082 (1968).

50. N. S. Poluéktưv, N. I. Smirdova, and N. P. Efryushina, Zh. Anal. KhIm., 25, 715 (1970).

51. P. D. Johnson in "Luminescence of Inorganic Solids," P. Goldberg, Ed., Academ1c Press, New York, N.Y., 1966, Chapter 5. 
52. A. K. Trotimov, Bul1. Acad. Sc1. USSR, Phys. Ser., 25, 453, (1961).

53. Lyuj1 Ozawa and Takao Toryu, Ana1. Chem., 40, 187 (1968).

54. R. A. Buchanan and K. A. Wickersheim, IEEE Trans. Nucl. Sc1., NS-15, 95 (1968).

55. A. N. Karyakin, L: I. Ankina, and Le Viet Binh, Zh. Anal. Khim., 24, 1156 (1969).

56. S. Natansohn, J. Electrochem. Soc., 116, 1250 (1969).

57. R. C. Ropp, J. Electrochem. Soc., 115, 841. (1968).

58. K. A. Wickersheim, R. V. Alves, and.R. A. Buchanan, IEEE Trans. Nuc1. Sci., NS-17, 57 (1970).

59. F. C. Palilla, A. K. Levine, and M. Rinkevics, J. Electrochem. Soc., 112,776 (1965).

60. L. H. Brixner and E. Abramson, J. Electrochem. Soc., 112, 70 (1965).

61. N. S. Poluéktov and S. A. Gava, Zavod. Lab., 35, 1458 (1969).

62. R. C. Ropp, J. Electrochem. Soc., 11.5, 940 (1968).

63. N. S. Poluéktov and S. A. Gava, Zh. Anal. Khim., 25, 1735 (1969).

64. A. P. D'Silva, Iowa State University, personal communication, 1974 .

65. C. Duval, "Inorganic Thermogravimetric Analysis," Elsevier, New York, N.Y., 1963, p 570.

66. W. W. Wendlandt and J, L. Bear, J. Inorg. Nuc1. Chem., 12, 276 (1960).

67. H. V. Leverenz, "An Introduction to the Luminescence in Solids," Wiley, New York, N.Y., 1968.

68. M. R. Royce and S. M. Thomsen, U.S. Patent 3502590 (1970).

69. J. R. Van Wazer, "Phosphorous and Its Compounds," Vol. I, Interscience, New York, N.Y., 1958, p 503.

70. F. C. Palilla, A. K. Levine, and M. Rinkevice in "Proceedlings of the International Conference on Luminescence," Budapest, 1966, G. Szigeti, Ed., Akadém1a1 Kiad6, Budapest, Hungary, 1968, pp 1639-1645. 
71. C. Duval, "Inorganic Thermogravimetric Analysis," Elsevier, New York, N.Y., 1963, p 295.

72. W. Gerlach and E. Schweitzer, "Foundations and Methods of Chemical Analysis by the Emission Spectrum," Adam H1lger, London, 1929, Chapter V.

73. N. S. Poluéktov, R. A. Vitkun, and S. A. Gava; Zh. Anal. Khim., 24, 693 (1969).

74. H. V. Leverenz, "An Introduction to Luminescence in Solids," Wiley, New York, N.Y., 1968, pp 70-80, p 328.

75. L. I. Ankina, A. V. Karyakin, and Le Viet Binh, Zh. Anal. Khim., 25, 1731 (1970).

76. N. I. Smirdova and E. P. Efryushina, Zavod. Lab., 36, 1183.(1970).

77. N. S. Poluéktov, N. I. Smirdova, and E. P. Efryushina, Zh. Anal. Kh1m., 25, 1902 (1970).

78. Sh. G. Melamed, A. V. Antonov, and L. V. Kulevsk1, Zavod. Lab., 33, 712 (1967).

79. Tsuyosh1 Kano and Yushiro Otomo, J. Electrochem. Soc., 116, 64 (1969).

80. H. Kalser, "Two Papers on the Limft of Detection of a Complete Analytical Procedure," Adam Hilger, London, 1968. 


\section{ACKNOWLEDGMENTS}

I would like to express my deep appreclation for the guidance and assistance gdven to me during my stay at Iowa State University by Dr. V. A. Fassel.

In addition, I would like to thank Arthur P. D'Silva without whose direction, advice, and help this work would never have been completed.

Spectal thanks to Dr. Richard N. Kniseley whose answering of questions and critical reading of this thesis helped immensely not only in the completion of this work, but also in the development of my scientific knowledge:

Thanks to Robert J. Conzemius and Vera J. Peterson for the mass spectroscopic determinations of the trace Impurities in the unknown samples, and also to Harvey Burkholder for supplying the purifled rare earth metals and compounds used in this work.

I am grateful to my parents, Mr. and Mrs. E. W. Tritten, for the support, encouragement, and love they have given me.

I will never be able to express my love and gratitude to my wife, Marcla, for her fulth, patience, friendship and love. 